\title{
Cerebral blood flow changes after a day of wake, sleep,
}

\section{and sleep deprivation}

Torbjørn Elvsåshagen*1,2,3, Henri JMM Mutsaerts*4,5, Nathalia Zak¹, Linn B Norbom¹, Sophia H Quraishi ${ }^{6}$, Per Ø Pedersen³ ${ }^{3}$ Ulrik F Malt ${ }^{3,7}$, Lars T Westlye ${ }^{1,8}$, Eus JW van Someren ${ }^{9,10,11,}$ Atle Bjørnerud $8,12,13$, Inge R Groote ${ }^{12}$. ${ }^{*}$ These authors contributed equally to this work

${ }^{1}$ Norwegian Centre for Mental Disorders Research (NORMENT), KG Jebsen Centre for Psychosis Research, Oslo University Hospital, Norway

${ }^{2}$ Department of Neurology, Oslo University Hospital, Norway

${ }^{3}$ Institute of Clinical Medicine, University of Oslo, Norway

${ }^{4}$ Cognitive Neurology Research Unit, Sunnybrook Health Sciences Centre, Toronto, Canada

${ }^{5}$ Department of Radiology, Amsterdam University Medical Center, The Netherlands

${ }^{6}$ Barnard College, Columbia University, New York, USA

${ }^{7}$ Department of Research and Education, Oslo University Hospital, Norway

${ }^{8}$ Department of Psychology, University of Oslo, Norway

${ }^{9}$ Department of Sleep and Cognition, Netherlands Institute for Neuroscience, Amsterdam, The Netherlands

${ }^{10}$ Department of Psychiatry, Amsterdam University Medical Center, The Netherlands

${ }^{11}$ Department of Integrative Neurophysiology, Amsterdam University Medical Center, The Netherlands

${ }^{12}$ Department of Physics, University of Oslo, Norway

${ }^{13}$ The Intervention Center, Oslo University Hospital, Norway

Corresponding author
Torbjørn Elvsåshagen, MD, PhD
Norwegian Centre for Mental Disorders Research (NORMENT)
Oslo University Hospital, 0424 Oslo, Norway
Tel : +4723027350
E-mail: telvsaha@ous-hf.no

Running title: Sleep-wake-dependent CBF variation

Abstract word/body word/Tables/Figures: 287/5806/5/7 


\section{ABSTRACT}

Elucidating the neurobiological effects of sleep and wake is an important goal of the neurosciences. Whether and how human cerebral blood flow (CBF) changes during the sleep-wake cycle remain to be clarified. Based on the synaptic homeostasis hypothesis of sleep and wake, we hypothesized that a day of wake and a night of sleep deprivation would be associated with gray matter resting $\mathrm{CBF}(\mathrm{rCBF})$ increases and that sleep would be associated with $\mathrm{rCBF}$ decreases. Thirty-eight healthy adult males (age $22.1 \pm 2.5$ years) underwent arterial spin labeling perfusion magnetic resonance imaging at three time points: in the morning after a regular night's sleep, the evening of the same day, and the next morning, either after total sleep deprivation $(n=19)$ or a night of sleep $(n=19)$. All analyses were adjusted for hematocrit and head motion. rCBF increased from morning to evening and decreased after a night of sleep. These effects were most prominent in bilateral hippocampus, amygdala, thalamus, and in the occipital and sensorimotor cortices. Group $\mathrm{x}$ time interaction analyses for evening versus next morning revealed significant interaction in bilateral lateral and medial occipital cortices and in bilateral insula, driven by rCBF increases in the sleep deprived individuals and decreases in the sleepers, respectively. Furthermore, group $\mathrm{x}$ time interaction analyses for first morning versus next morning showed significant effects in medial and lateral occipital cortices, in anterior cingulate gyrus, and in the insula, in both hemispheres. These effects were mainly driven by CBF increases from TP1 to TP3 in the sleep deprived individuals. There were no associations between the $\mathrm{rCBF}$ changes and sleep characteristics, vigilant attention, or subjective sleepiness that remained significant after adjustments for multiple analyses. Altogether, 
these results encourage future studies to clarify mechanisms underlying sleep-related rCBF changes. 


\section{INTRODUCTION}

Sleep is an enigmatic, evolutionarily conserved process required for human health and functioning ${ }^{1-3}$. Sleep disturbances are common in the general population ${ }^{4-7}$ and associated with impaired cognitive performance, lowered work productivity, elevated risk of accidents, and increased prevalence of chronic somatic illnesses ${ }^{2,8,9}$. Sleep-wake cycle disturbances are also frequent features of neuropsychiatric and neurological disorders ${ }^{10,11}$ and sleep deprivation can have rapid antidepressive effects in mood disorders ${ }^{12,13}$. The incomplete understanding of sleep and wake processes is one important factor underlying the vast detrimental health effects and societal costs of sleep insufficiency in modern society ${ }^{2,8,9}$. Elucidating the neurobiological effects of waking and sleep is therefore an important goal in basic and clinical neurosciences.

The dominating theory of sleep regulation is the two-process model ${ }^{14,15}$. This model distinguishes between circadian and homeostatic mechanisms that together determine the timing of sleep and wake. The circadian component - process C - is a near- $24 \mathrm{~h}$ selfsustained oscillator influencing the sleep-wake cycle, and is governed by the suprachiasmatic nucleus (SCN) in the anterior hypothalamus ${ }^{16}$. The homeostatic component - process S - accumulates exponentially during wakefulness and is discharged during sleep. Although the neural substrates of process S remain to be clarified, the synaptic homeostasis hypothesis posits that process $S$ reflects synaptic strength ${ }^{17,18}$. This hypothesis is supported by a growing body of animal and human evidence ${ }^{19-25}$ and suggests that learning and experience during wake promote synaptic strengthening, whereas sleep favors synaptic 
downscaling ${ }^{17}$.

The majority of the brain's energy is used on synapses and synaptic strengthening increases the metabolic $\operatorname{cost}^{26,27}$. One prediction of the synaptic homeostasis hypothesis is therefore that cerebral metabolic rate (CMR), and, in turn, cerebral blood flow (CBF) of gray matter, should increase after wake and decrease after sleep ${ }^{17,28}$. Previous studies of CMR and CBF after wake and sleep have reported mixed results; some reports suggested that CBF and CMR fluctuate over the course of a single day ${ }^{29-31}$, whereas other studies did not find such variation ${ }^{32}$. Thus, whether CMR and CBF exhibit sleep-wake cycle-dependent changes remains to be clarified. In the present study, we investigated resting CBF (rCBF) in healthy young male adults after day of wake, sleep, and sleep deprivation using arterial spin labeling (ASL) perfusion magnetic resonance imaging (MRI) ${ }^{33}$. We hypothesized that a day of wake and a night of sleep deprivation would be associated with widespread gray matter rCBF increases and that sleep would be associated with rCBF decreases, as predicted by the synaptic homeostasis hypothesis ${ }^{17,28}$. Secondly, we examined whether rCBF changes after wake and sleep were associated with chronotype, sleep habits, and vigilant attention. 


\section{MATERIALS AND METHODS}

\subsection{Ethics statement}

Ethical approval was obtained from the Norwegian South East Regional Ethics Committee and all procedures were in line with the declaration of Helsinki. All participants signed informed consent prior to enrolment and received NOK 500 for their participation.

\subsection{Descriptive characteristics and study design}

Forty right-handed, healthy, adult male volunteers were included. Functional and structural MRI data from overlapping samples were previously investigated ${ }^{34-36}$. We included males only, in order to exclude potential variability due to hormonal cycles. One individual was excluded from the study due to head motion artifacts, and another did not finalize all MRI sessions. The mean age of the final sample $(n=38)$ was $22.1 \pm 2.5$ years (Table 1$)$. Before study inclusion, all participants were screened for current and previous psychiatric and somatic illnesses. Exclusion criteria were: history of sleep disorders, psychiatric, neurological or chronic somatic disorders, current acute somatic illnesses, use of psychotropic drugs, alcohol or drug use disorders, former head injury with loss of consciousness for more than one minute, and standard MRI exclusion criteria.

The study protocol is summarized in Figure 1A. All participants underwent MRI at the Oslo University Hospital in the morning after a night of regular sleep at home (time point $(\mathrm{TP})=$ 1) and the same evening after approximately 14 hours of waking (TP2). Participants were allowed to leave the hospital between TP1 and TP2, and were instructed not to sleep during 
this time. Participants were then assigned either to a sleep group $(n=19)$ or a sleep deprivation group $(\mathrm{n}=19)$. The sleep group and the sleep deprivation group were then scanned the next morning (TP3) after a night of sleep at home or after a night of total sleep deprivation, respectively. The sleep deprivation group was supervised at the hospital to ensure they stayed awake. Physical exercise and consumption of alcohol, caffeine and nicotine were prohibited from the night before the study day until study completion. No intake of food or energy-containing fluids was allowed three hours prior to each MRI session.

\subsection{Assessment of wake and sleep parameters and vigilant attention}

Participants were interviewed about their sleep habits, including their sleep duration on the night, the week, and the month before study participation. Chronotype was measured using Horne-Östberg Morningness-Eveningness (HOME) questionnaire ${ }^{37}$, whereas general level of daytime sleepiness propensity was assessed using the Epworth Sleepiness Scale $(E S S)^{38}$. Sleep quality the last month was measured using Pittsburgh Sleep Quality Index $(P S Q I)^{39}$. Subjective sleepiness was assessed at each time point using the Karolinska Sleepiness Scale $(\mathrm{KSS})^{40}$, which is a nine point Likert-type scale ranging from "Extremely alert" (1) to "extremely sleepy" (9). To obtain an objective estimate of vigilant attention at all TPs, the participants performed the attention network task ${ }^{41}$ immediately after each MRI acquisition. This task yields reaction time measures in three different conditions by flankering target stimuli with congruent, incongruent or neutral stimuli, thereby altering the difficulty of the task (neutral < congruent $<$ incongruent). As described previously ${ }^{35}$, we 
estimated the intra-individual variation in reaction time, defined as the coefficient of variation in response time, and mean reaction time across the three attention network task flanker conditions.

\subsection{Measurement of blood hematocrit}

To assess potential fluctuations in longitudinal relaxation rate of blood $\left(\mathrm{T}_{\mathrm{b}} \mathrm{b}\right)$, venous blood was drawn from the antecubal vein immediately after each scan, and hematocrit (Hct) was measured using a Sell-Dyn Sapphire Hematology System (Abbott Diagnostics, Illinois, US). The coefficient of variation of the individual analysis system in use was $2.4 \%$. Hct values were used to derive Hct-corrected T1-relaxation times in blood ${ }^{42}$.

\subsection{MRI acquisition}

MRI was performed on a 3T Achieva scanner (Philips Healthcare, Best, the Netherlands), equipped with an 8-channel head coil (InVivo, Gainesville, FL, US) and foam padding to restrict head motion. Participants were instructed to have their eyes open during all ASL scans. $\mathrm{rCBF}$ measurements were performed using a pseudo-continuous $\mathrm{ASL}^{43}$ sequence with a gradient-echo single-shot echo-planar imaging readout with acquisition parameters: matrix $=64 \times 64$, field-of-view $=210 \times 210 \mathrm{~mm}, 22$ axial $6 \mathrm{~mm}$ slices (no gap), echo time $/$ repetition time $(\mathrm{TR})=11 / 4400 \mathrm{~ms}$, flip angle $=90$ degrees, SENSE factor $=2,60$ control-label pairs, total scan duration $=9$ min. Labeling was performed with a train of Hanning-shaped RF pulses - flip angle $=18^{\circ}$, pulse duration $=0.5 \mathrm{~ms}-$ with an inter-pulse

interval of $1 \mathrm{~ms}$ in a balanced gradient scheme ${ }^{44}$, with post-label delay $=1800-2640 \mathrm{~ms}$ 
(from first to last slice) and labeling duration $=1800 \mathrm{~ms}$. The labeling plane was positioned based on a time-of-flight angiogram. Background suppression was achieved by applying a saturation pulse before labeling and two inversion pulses during the post-label delay. An M0 reference scan was acquired with the same ASL readout without background suppression or labeling (TR=12s, 3 averages). An 1x1x1.2 mm 3D T1-weighted anatomic image was acquired for segmentation and registration purposes.

\subsection{ASL image processing}

SPM12 (www.fil.ion.ucl.ac.uk/spm/software/spm12) and ExploreASL were used for image processing and statistical analyses ${ }^{45,46}$, including rigid-body motion correction accounting for signal intensity differences between control and label images ${ }^{47}$, threshold-free outlier exclusion based on head motion ${ }^{48}$ and a single compartment quantification model, assuming that the label decay is determined by the $\mathrm{T} 1_{\mathrm{b}}$ only $^{33}$. For each $\mathrm{TP}$ and for the sleep and sleep deprived groups separately, a group-average $\mathrm{T} 1_{\mathrm{b}}$ was calculated from Hct measurements ${ }^{42}$, which were employed in the rCBF quantification. Each 3D T1-weighted anatomical scan was segmented into gray and white matter tissue probability maps. All CBF maps were rigid-body registered to the gray matter probability maps. A Diffeomorphic Anatomical Registration analysis using Exponentiated Lie algebra (DARTEL) ${ }^{49}$ template was created using the gray and white matter probability maps. The resulting DARTEL transformations were applied to the CBF maps. All transformations were combined into a single $4^{\text {th }}$ degree B-spline interpolation for each scan. 


\subsection{Voxel-based analysis and additional statistical tests}

The rCBF maps were masked slice-wise at $50 \%$ of the maximum MNI GM tissue probability, excluding regions prone for susceptibility artifacts: the inferior cerebellum, inferotemporal lobe, and orbitofrontal cortex. Before the voxel-based analysis, the rCBF maps were smoothed using a $6.4 \times 6.4 \times 6.4 \mathrm{~mm}$ full-width half-maximum Gaussian kernel, constrained by the mask. General linear models were run to examine the effects of a day of wake and a night of sleep deprivation or sleep on $\mathrm{rCBF}$. The statistical significance was determined using cluster size inference with an initial cluster forming threshold of $p<0.001$, where clusters with a corrected family-wise error rate of $p<0.05$ were considered significant. Since the experimental conditions were identical for the sleep group and the sleep group between TP1 and TP2, we first examined the effect of time across all participants for the TP1-TP2 contrast. Next, we conducted group x time interaction analyses for the TP2-TP3 and TP1TP3 contrasts. These analyses were run to test the hypotheses of the study. We also ran secondary analyses within the sleep group and within the sleep deprivation group separately, to further explore the effects of sleep and sleep deprivation on rCBF.

Averaged rCBF values were computed in clusters showing significant changes across all participants after a day of waking - TP1 versus TP2 - and in clusters showing significant group x time interaction effects for TP2 versus TP3 and TP1 versus TP3. Associations between rCBF within the significant clusters and HOME, ESS, PSQI and KSS scores, intraindividual variation in reaction time and mean reaction time of the attention network task, and times of and intervals between the MRI scans were conducted using SPSS Statistics, 
version 25 for Windows (IBM Corp, Armonk, NY, US). Additional linear mixed models for repeated measurements were employed to adjust for potential effects of head motion on rCBF after wake and sleep, summarizing the six parameters of head motion into a single root-mean-square vector. 


\section{RESULTS}

\subsection{Characteristics and sleep-wake habits}

Table 1 summarizes the participants' characteristics and sleep-related parameters. All participants had a regular sleep-wake cycle and their self-reported sleep durations in the last month and last week were consistent with the average sleep duration of young Norwegian adults ${ }^{50}$. There was no difference between the groups in number of hours of selfreported sleep the night before TP1 or in hours of sleep per night last week and month (all $p>0.44)$. Furthermore, the sleep reported by the sleep group did not differ between the night before TP1 and the night before TP3 ( $p=0.1)$. However, the sleep group reported less sleep the night before TP3 than their average hours of sleep last week and month (both $p<0.001)$. Additionally, all participants reported less sleep the night before TP1 than their average hours of sleep in the last week or last month (both $p<0.001$ ). Whereas the MRI scanning times for TP1 were similar $(p=0.3)$ for the sleep group $(08 \mathrm{~h} 21 \pm 00 \mathrm{~h} 47)$ and the sleep deprivation group $(08 \mathrm{~h} 36 \pm 00 \mathrm{~h} 36)$, the deprived group $(23 \mathrm{~h} 00 \pm 00 \mathrm{~h} 31)$ was scanned $\sim 80$ minutes later $(p<0.001)$ in the evening compared to the sleep group $(21 \mathrm{~h} 42 \pm$ 00h31), and $\sim 1.5$ hours earlier in the next morning $(08 \mathrm{~h} 13 \pm 00 \mathrm{~h} 55$ and $06 \mathrm{~h} 48 \pm 00 \mathrm{~h} 30$ for sleepers and deprived, respectively, $p<0.001$; Figure 1A). Hct differed between the TPs across all participants $(p<0.03)$, leading to the blood T1 values described in Table 2 , which were used to correct rCBF quantification. Although head motion was small, it was increased for TP3 in the sleep deprived group (average root-mean-square motion $0.097 \pm 0.015 \mathrm{~mm}$ at TP3 versus $0.070 \pm 0.010$ and $0.075 \pm 0.013 \mathrm{~mm}$ for TP1 and TP2, respectively, $p<0.0001$ ). There were no other head motion differences between groups or TPs (all $p$ 
values $>0.12$ ).

\section{2 Vigilant attention and subjective sleepiness}

There were time and time $\mathrm{x}$ group interactions effects on the variation in reaction time (time: $F_{2,35}=15.6, p<0.001$; time x group: $F_{2,35}=6.9, p=0.003$ ), mean reaction time (time: $F_{2,35}=6.9, p=0.003$; time $\mathrm{x}$ group: $F_{2,35}=27.7, p<0.001$ ), and KSS (time: $F_{2,35}=28.8, p<0.001$; time $\mathrm{x}$ group: $F_{2,35}=30.8, p<0.001$ ), with robust increases in the sleep deprivation group at TP3 (Figures 1B-D).

\subsection{Resting CBF changes after a day of waking (TP1 versus TP2)}

Across all participants $(n=38)$, there were increases in rCBF from TP1 to TP2 in four clusters (Figure 2 and Table 3). The rCBF increases within these clusters ranged from 7.5 to $11 \%$ and mainly involved bilateral hippocampus and amygdala, bilateral thalamus, and bilateral precentral and postcentral gyrus. There were no areas where rCBF decreased over the course of the day. The rCBF increases within the four clusters remained significant after adjusting for head motion (all $p<0.002$ ). There were no significant associations between time of MRI at TP2 and rCBF within the four clusters of Table 3 (all $p$ values >0.2). Moreover, there were no significant relationships between time from TP1 to TP2 and the rCBF changes within the four clusters from TP1 to TP2 (all $p$ values $>0.7$ ).

\subsection{Resting CBF changes from the evening to the next morning (TP2 versus TP3)}

The whole-brain analyses for TP2 versus TP3 showed a main effect of time in bilateral 
hippocampus and thalamus (Figure $3 \mathrm{a}$ and Table $4 \mathrm{a}$ ). The group $\mathrm{x}$ time interaction analyses revealed clusters with significant interaction mainly in bilateral lateral and medial occipital cortices and in bilateral insula (Figure 3b). These effects were driven by rCBF increases in the sleep deprived individuals and decreases in the sleepers, respectively (Table 4b) and remained significant after adjustments for head motion (all $p<0.001$ ). There were no significant associations between time of MRI at TP3 and $\mathrm{rCBF}$ within the five clusters of Table $4 \mathrm{~b}$ (all $p$ values $>0.2$ ). Moreover, there were no significant relationships between time from TP2 to TP3 and the rCBF changes within the five clusters from TP2 to TP3 in the sleep group or in the sleep deprived group (all $p$ values $>0.3$ ). We also examined rCBF changes from TP2 to TP3 within the sleep group $(n=19)$ and found decreases in bilateral hippocampus and amygdala and right lateral temporal and occipital cortices (Figure 4a). Within the sleep deprived group, there were rCBF increases in bilateral medial occipital and parietal cortices and CBF decreases in bilateral thalamus from TP2 to TP3 (Figure 4b). Figure 5 shows the results of the conjunction analysis of changes from TP1 to TP2 across all individuals and changes from TP2 to TP3 in the sleep group, with overlap for bilateral hippocampus and amygdala.

\subsection{Resting CBF changes from the first to the second morning (TP1 versus TP3)}

The whole-brain analyses for TP1 versus TP3 showed a main effect of time primarily in right thalamus and bilateral precentral and postcentral gyrus (Figure 6a and Table 5a). The group x time interaction analyses revealed clusters with significant interaction mainly in medial and lateral occipital cortices, in anterior cingulate gyrus and in the insula, in both 
hemispheres (Figure 6b). These effects were mainly driven by CBF increases from TP1 to TP3 in the sleep deprived individuals (Table 5b) and remained significant after adjustments for head motion (all $p$ values $<0.02$ ). There were no significant associations between time of MRI at TP3 and rCBF within the five clusters of Table $5 \mathrm{~b}$ (all $p$ values $>0.2$ ). Moreover, there were no significant relationships between time from TP1 to TP3 and the rCBF changes within the five clusters from TP1 to TP3 in the sleep group or in the sleep deprived group (all $p$ values $>0.2$ ). Within the sleep deprived group, there were CBF increases mainly in medial and lateral occipital cortices, in the insula, and in somatosensory and motor cortices, in both hemispheres (Figure 7). The sleep deprived group also showed CBF decreases from TP1 to TP3, primarily in right thalamus, left cerebellum, and in bilateral lateral parietal cortices. There were no significant CBF changes from TP1 to TP3 in the sleep group (data not shown).

\subsection{Resting CBF, sleep-wake characteristics, vigilant attention, and subjective sleepiness after a day of wake and sleep deprivation}

We first examined the relationships between $\mathrm{rCBF}$ at TP2 within the significant clusters of Table 3 and sleep-wake characteristics, vigilant attention, and subjective sleepiness. Here, there were positive associations between variation in reaction time and $\mathrm{rCBF}$ in clusters II $(r=0.32, p=0.05)$ and IV ( $r=0.43, p=0.008)$ at TP2 across all individuals (Supplemental Table 1). However, none of these remained significant after adjustments for multiple analyses $(N=24$; Bonferroni-corrected significance threshold of $p=0.002)$. We then ran analyses for the relationships between changes within the significant clusters of Table 3 from TP1 to 
TP2 and changes in variation in reaction time, changes in mean reaction time, and changes in KSS, from TP1 to TP2. Here, there were no significant associations (all $p>0.24$ ).

Next, we ran association analyses for the significant clusters of Table 4b (TP2 versus TP3) for the sleep deprived individuals and the sleepers separately. There was a negative association between $\mathrm{rCBF}$ of cluster IV in Table $4 \mathrm{~b}$ and HOME score $(r=-0.65, p=0.003)$ in the sleep group (Supplemental Table 2a), yet this was not significant after correcting for multiple analyses (60 analyses (30 per group); Bonferroni-corrected significance threshold of $p=0.0008$ ). We then conducted correlation analyses of the relationships between changes within the significant clusters of Table $4 \mathrm{~b}$ from TP2 to TP3 and changes in variation in reaction time, changes in mean reaction time, and changes in KSS, from TP2 to TP3. These analyses showed a negative association between $\mathrm{rCBF}$ changes within cluster IV and changes in mean reaction time in the sleep deprived group $(r=-0.48, p=0.04)$; otherwise, there were no significant associations in the sleep group or in the sleep deprived group (all $p>0.05)$.

We also ran association analyses for the significant clusters of Table 5b (TP1 versus TP3). There was a negative association between rCBF of cluster $\mathrm{V}$ and HOME score $(r=-0.59$, $p=0.008$ ) in the sleepers (Supplemental Table 3a), yet this was not significant after adjusting for multiple analyses (60 analyses; Bonferroni-corrected significance threshold of $p=0.0008$ ). Otherwise, all $p$ values were $>0.01$ in the sleep group and in the sleep deprivation group (Supplemental Table 3). We then ran correlation analyses of the 
relationships between changes within the significant clusters of Table 5b from TP1 to TP3 and changes in variation in reaction time, changes in mean reaction time, and changes in KSS, from TP1 to TP3. Here, there were negative associations between changes in KSS and changes in rCBF of clusters IV (rho=-0.50, $p=0.03)$ and V (rho=-0.55, $p=0.01)$ in the sleep deprived individuals; otherwise, there were no significant associations in the sleep group or in the sleep deprived group (all $p>0.05$ ). The latter associations did not remain significant after adjustments for multiple analyses (30 analyses (15 per group); Bonferroni-corrected significance threshold of $p=0.002$ ). 


\section{DISCUSSION}

In this study, we found that a day of wake - TP1 versus TP2 - was associated with rCBF increases in bilateral hippocampus, amygdala, thalamus, and sensorimotor cortices. The analyses also indicated that these increases were reversed by sleep, particularly those involving the hippocampus and the amygdala. Group (sleep versus sleep deprivation) x time interaction analyses for evening versus next morning (TP2 versus TP3) revealed significant interaction in bilateral lateral and medial occipital cortices and in bilateral insula, driven by further rCBF increases in the sleep deprived individuals and decreases in the sleepers, respectively. Moreover, group x time interaction analyses for first morning versus next morning (TP1 versus TP3) showed significant effects in medial and lateral occipital cortices, in anterior cingulate gyrus, and in the insula, in both hemispheres. These effects were mainly driven by CBF increases from TP1 to TP3 in the sleep deprived individuals. There were no associations between $\mathrm{rCBF}$ in significant clusters and sleep-wake characteristics, vigilant attention, and subjective sleepiness that remained significant after adjustments for multiple analyses.

\subsection{Resting CBF increases after a day of wake and decreases after a night of sleep}

The first main finding of this study was that rCBF increased from morning to evening and decreased after a night of sleep. These rCBF changes were most prominent in the bilateral hippocampus, amygdala, thalamus, and in sensorimotor cortices. There was no difference in rCBF between the first and the second morning sessions of the sleep group, indicating that rCBF resets to the morning level after a night of sleep. 
Several studies investigated CBF and CMR during the normal sleep-wake cycle. One Doppler ultrasonography study found decreased CBF after a night of sleep relative to presleep in six participants ${ }^{29}$. Reduced CBF was also found in 10 participants during sleep using the KetySchmidt method ${ }^{51}$. Our findings are consistent with a positron emission tomography (PET) study of 20 sleep deprived participants, that found a 18\% global rCBF decrease after sleep with most prominent decreases in the occipital and temporal cortices and in the hippocampus ${ }^{30}$. Another PET study of 22 participants showed a trend towards increased the resting global CMR of glucose (rCMRglc) from morning to afternoon ${ }^{52}$. A mixed pattern of increases and decreases in the metabolism of the cortex and increases in brainstem and hypothalamic arousal centers were found when comparing evening with morning scans in a PET study of 10 participants ${ }^{53}$. However, a recent PET study of 10 participants quantified rCBF, rCMRglc and resting CMR of $\mathrm{O}_{2}$ and did not found a difference in flow or metabolic measures between morning and nighttime scans ${ }^{32}$. Moreover, an ASL study compared rCBF (of the cortical mantle only) in the morning ( 9AM) with afternoon $(\sim 5 \mathrm{PM})$ scans from another day in 13 participants and found no change in global $\mathrm{rCBF}^{31}$, yet reported a regional rCBF decrease from morning to afternoon in a core region of the default mode network $(\mathrm{DMN})^{54}$. Thus, the findings of the present study showing rCBF increases after wake and decreases after sleep are consistent with some $e^{29,30,51-53}$, but not all ${ }^{31,32}$ previous studies. Some of the inconsistencies may result from differences in employed method, study design, and sample size.

Further studies are needed to clarify the precise neural mechanisms underlying sleep-wake 
cycle-dependent $\mathrm{rCBF}$ changes found in the present study. These $\mathrm{rCBF}$ alterations after a day of wake and a night of sleep may be related to sleep-wake-dependent homeostatic factors, circadian variation, or a combination of these processes. Concerning homeostatic factors, a growing body of evidence supports the synaptic homeostasis hypothesis, which posits that wake and sleep are associated with synaptic strengthening and synaptic downscaling, respectively ${ }^{17,28}$. One important prediction of this hypothesis is that CMR and CBF should increase after wake and decrease after sleep ${ }^{17,28}$, since synaptic strengthening increases the metabolic $\operatorname{cost}^{26,27}$. Therefore, although speculative, the $\mathrm{rCBF}$ changes observed in the present study might, at least in part, be related to diurnal variation in cerebral synaptic strength and metabolic rate.

The rCBF changes in the thalamus after a day of wake and a night of sleep deprivation are of particular interest in relation to SCN-controlled arousal mechanisms of the brain. The dorsal paraventricular thalamus, formerly considered part of "the nonspecific thalamus", has recently been shown to modulate state-dependent behavior and is a possible anatomical link between hypothalamic control centers for circadian timing and sleep-wake regulation and the cerebral cortex ${ }^{55}$. The thalamic regions that showed $\mathrm{rCBF}$ changes after wake in the present study could represent a meeting point for the integration of SCN function onto the cortex. Although the pattern of $\mathrm{rCBF}$ changes observed in the present study could be related to sleep-wake-dependent homeostatic factors, e.g., synaptic homeostasis, these findings could also reflect potential SCN-mediated circadian variation in resting brain activity or an integration of these processes. 
The findings in the hippocampus and amygdala after wake and sleep, as observed in the present study, are interesting. The hippocampus has well-established roles in learning and memory consolidation ${ }^{1,28}$ and the amygdala is important for emotional learning and memory modulation ${ }^{56}$. Synaptic plasticity mechanisms, such as long-term potentiation, are likely neurobiological substrates for these processes ${ }^{1,28,57}$. Sleep, on the other hand, facilitates efficient encoding and storage of memories, possibly by synaptic strength regulation, and non-rapid eye movement (REM) sleep is believed to play important roles in renewing the next-day learning capacity ${ }^{1,58,59}$. Although more research is needed to elucidate the underlying neural processes, the present diurnal rCBF variation findings in the hippocampus and amygdala are in agreement with hypotheses for learning and memory-related synaptic alterations during wake and sleep.

\subsection{Resting CBF changes after total sleep deprivation}

The second main finding of the present study was that a night of sleep deprivation - TP2 versus TP3 - was associated with further $\mathrm{rCBF}$ increases in bilateral lateral and medial occipital cortices and in bilateral insula. In addition, the group $\mathrm{x}$ time interaction analyses for first morning versus next morning (TP1 versus TP3) indicated that the sleep deprivation was associated with rCBF increases in medial and lateral occipital cortices, in anterior cingulate gyrus, and in the insula, in both hemispheres.

The first systematic studies of effects of sleep deprivation on human cerebral function were conducted in the late $19^{\text {th }}$ century ${ }^{60}$, yet whether and how lack of sleep affects CBF and CMR 
remains to be clarified. An early study measured $\mathrm{rCBF}$ in 11 rested participants and 25 individuals sleep deprived for 20 hours with the Kety-Schmidt method and reported a nonsignificant increase in $\mathrm{rCBF}$ in the sleep deprived group ${ }^{61}$. A PET study of 17 participants sleep deprived for 24 hours found a decrease in global rCMRglc of $8 \%$, with widespread regional decreases, most prominent in the thalamus and in the frontal and parietal lobes ${ }^{62}$. Two other PET studies detected decreased thalamic metabolism ${ }^{63}$ and reduced metabolism in the frontal cortex, thalamus, and striatum ${ }^{64}$ after sleep deprivation. An ASL MRI study observed no global effect of partial sleep deprivation, yet reported frontoparietal rCBF decreases in a subgroup of participants with strong signs of drowsiness ${ }^{65}$. Another ASL study of 20 participants found increases in $\mathrm{rCBF}$ in early visual cortices after sleep deprivation ${ }^{66}$. Thus, although the number of studies conducted to date is limited, there is some evidence that sleep deprivation leads to rCBF or rCMRglc decreases in frontoparietal cortices as well as in the thalamus, and to $\mathrm{rCBF}$ increases in early visual cortices. These observations are - at least partly - consistent with the results of the present study.

The analyses indicated that 23 hours of sleep deprivation was associated with rCBF increases in bilateral insula and anterior cingulate gyrus. These regions are central hubs of the salience network and regulate the anti-correlation between the task-related central executive network and the $\mathrm{DMN}^{67}$. It has been hypothesized that sleep deprivation-related changes of insula activity could contribute to the unstable reciprocal inhibition between task-related activity and DMN activity found after insufficient sleep ${ }^{68}$. A recent rodent study also implicated the insula in sleep and wake regulation ${ }^{69}$. Here, lesions of the anterior insula 
resulted in decreased wakefulness and increased REM and non-REM sleep. Whether the insula and anterior cingulate gyrus are involved in wake and sleep regulation in humans should be addressed by future studies. We also found rCBF increases in somatosensory and motor cortices after sleep deprivation. These findings are in line with studies showing increased somatosensory evoked potentials ${ }^{70,71}$ and altered motor cortex excitability 72,73 after sleep deprivation. Although the precise substrates for increased evoked potentials, excitability changes, and rCBF increases within somatosensory and motor cortices remain to be elucidated, these findings together indicate that neural processing within these regions are affected by sleep deprivation.

The analyses within the sleep deprivation group suggested that sleep deprivation is associated with $\mathrm{rCBF}$ decreases in parietal association cortices. These findings are consistent with recent functional MRI experiments which have found reduced activity in lateral parietal regions after sleep deprivation during working-memory and attention tasks $^{68,74,75}$. The analysis restricted to the sleep deprivation group also suggested rCBF decreases in the thalamus, which is consistent with some previous studies detecting reduced thalamic metabolism after sleep deprivation ${ }^{62-64}$. The sleep deprivation-related rCBF reduction in the thalamus of the present study may reflect decreased thalamic activity, which could lead to reduced arousal and cortical rCBF reductions .

There were cortical rCBF increases from morning to evening and further increases in bilateral occipital and temporal cortices and insula after a night of sleep deprivation. While 
the $\mathrm{rCBF}$ increases from morning to evening could reflect sleep-wake-dependent homeostatic factors, circadian variation, or a combination of these processes, it is more likely that the changes in $\mathrm{rCBF}$ after sleep deprivation reflect homeostatic mechanisms. Whether these "process S-like" rCBF changes are related to synaptic strength alterations or other neural processes remains to be clarified by future studies.

\subsection{Resting CBF, sleep-wake characteristics, vigilant attention, and subjective sleepiness}

The analyses for relationships between the rCBF changes and sleep characteristics, vigilant attention, and subjective sleepiness indicated a few noteworthy associations. First, there was a positive association between variation in reaction time and $\mathrm{rCBF}$ of clusters II and IV, which included left and right somatosensory and motor cortices, at TP2. Associations between rCBF and drowsiness indices were also observed in a previous sleep deprivation study ${ }^{65}$. However, the latter study found that $\mathrm{rCBF}$ decreased in the right fronto-parietal attentional network after partial sleep deprivation in participants with strong signs of drowsiness and that $\mathrm{rCBF}$ increased in the basal forebrain and posterior cingulate cortex of participants who remained alert after sleep restriction. The discrepancy between the results of the latter and the present study might be related to experimental design, e.g., partial sleep deprivation ${ }^{65}$ versus total sleep deprivation, and methods, e.g., drowsiness rating based on eye-video recorded during the $\mathrm{MRI}^{65}$ versus the attention network task employed in the present study. Second, there was a negative association between HOME score and decreases in $\mathrm{rCBF}$ of cluster $\mathrm{V}$, mainly involving the right insula, in the sleep 
group, indicating greater $\mathrm{rCBF}$ decreases after sleep in individuals with higher "morningness" scores, at TP3. Finally, there was a negative association between changes in KSS score and rCBF changes from TP1 to TP3 in clusters IV and V, primarily involving bilateral insula, indicating smaller KSS score changes in individuals with greater rCBF changes. The latter findings are noteworthy given the potential contributions of the insula to wakefulness regulation. Importantly, however, there were no associations that remained significant after adjustments for multiple analyses and further studies are needed to clarify the relationship between $\mathrm{rCBF}$ changes and sleep characteristics, vigilant attention, and subjective sleepiness.

\subsection{Methodological considerations and implications for future research}

There are several methodological aspects of this study that warrant comment. First, the current study is the largest neuroimaging study to date for rCBF changes after wake, sleep, and sleep deprivation. Second, the participants reported less sleep the night before TP1 than their usual sleep duration. However, assuming that sleep and wakefulness have opposite effects on rCBF, we would expect reduced sleep duration before TP1 to attenuate the waking-related $\mathrm{rCBF}$ increases that are observed in this study. Likewise, the fact that the sleep group reported less sleep than usual before TP3 might have resulted in an underestimation of the effects of sleep on rCBF. Third, several factors may affect rCBF measurements ${ }^{76}$, some of which could vary in a rhythmical manner and therefore influence the $\mathrm{rCBF}$ measurements in the present study. Although our experiment was already controlled for several potential confounders, including hydration, hct and head motion, a 
more rigid control regime could be exerted on potential Zeitgeber signals such as physical external stimuli and cognitive workload during wake. Fourth, the sleep group slept at home, whereas the sleep deprivation group was monitored at the hospital. This could have resulted in differences in light exposure and homeostatic cues that, at least in theory, could have influenced the rCBF of the sleep group. Future studies should ideally house all participants in a sleep laboratory under the same environmental conditions. Fifth, there were differences between the sleep and the sleep deprivation groups in the times of the second and third MRI. Although the time differences were relatively small, it remains unclear whether these may have affected the rCBF results. However, there were no significant associations between the rCBF of the significant clusters and the times of and the intervals between the MRI scans. Thus, it seems unlikely that the MRI time differences have significantly influenced the rCBF group differences of this study. Sixth, an important limitation of the present study is that we cannot rule out that participants had brief periods of sleep during the ASL MRI, since no eye tracking or electroencephalography data was collected during scanning. However, we believe it is unlikely that this has substantially affected the results of the present study for several reasons. The ASL sequence was played before structural MRI sequences and we are confident that all participants were awake during the structural scans since they then completed a continuous subtraction task that was monitored by a research assistant. Moreover, the risk of falling asleep should be lower in the early part than in the later part of the MRI session. All participants were asked whether they could have slept during the MRI after completing the scanning sessions, and all reported that they had remained awake. Finally, there is no evidence for sleep-induced 
increases in rCBF; thus it seems highly unlikely that $\mathrm{rCBF}$ increases after sleep deprivation, as indicated by the present study, are caused by within-scanner sleep. Nonetheless, yet it seems unlikely that the participants had longer periods of sleep during the MRI sessions, participants could have had very brief periods of microsleep that they were not aware took place. Whether the regional $\mathrm{rCBF}$ decreases found after sleep deprivation were related to brief microsleep, increased drowsiness, or sleep-wake-dependent homeostatic factors should be clarified by future studies.

Apart from the relevance of our findings within the context of sleep-wake biology, the results of this study indicating morning-evening variation in rCBF may have practical implications for future neuroimaging studies. For example, it is not uncommon that MRI data is acquired from patients in the morning due to the presence of qualified health personnel and from healthy controls in the afternoon and evening. If there indeed exists a systematic variation in rCBF from morning to evening, this could confound group comparisons. Moreover, recent studies also observed time-of-day effects on other MRI modalities ${ }^{34-36,77-79}$. Future studies should therefore take into account the possibility of timeof-day effects on functional and structural neuroimaging indices.

\subsection{Conclusion}

The findings of the present study suggest that rCBF increases from morning to evening in in bilateral hippocampus, amygdala, thalamus, and sensorimotor cortices and that these changes reverse after a night of sleep. The current study also indicates that sleep 
deprivation is associated with further increases in rCBF in occipital and temporal cortices and in the insula. Further studies are needed to clarify the mechanisms underlying rCBF changes after wake, sleep, and sleep deprivation. 


\section{ACKNOWLEDGMENTS}

The authors are grateful to the Department of Neurology, Oslo University Hospital, for assistance with blood collection and dr. PW Hales for his help in performing the Hct/T1 ${ }_{b}$ corrections.

\section{FUNDING}

This study was funded by the Research Council of Norway, the South-Eastern Norway Regional Health Authority (grant no 2017090), Oslo University Hospital, and a research grant from Mrs. Throne-Holst. N.Z. was funded by the Ebbe Frøland foundation and H.J.M is supported by Amsterdam Neuroscience funding.

\section{AUTHOR CONTRIBUTIONS}

A.B., T.E., and I.R.G., designed the study. T.E., N.Z., L.N., and P.Ø.P. collected the data. T.E., I.R.G., and H.J.M. analyzed the data. T.E., I.R.G. and H.J.M. prepared the manuscript and all authors edited and approved the final manuscript. 


\section{REFERENCES}

1. Walker MP, Stickgold R. Sleep, memory, and plasticity. Annu Rev Psychol 2006; 57: 139-166.

2. $\quad$ Luyster FS, Strollo PJ, Jr., Zee PC, Walsh JK. Sleep: a health imperative. Sleep 2012; 35: 727-734.

3. Cirelli $\mathrm{C}$. The genetic and molecular regulation of sleep: from fruit flies to humans. Nature reviews Neuroscience 2009; 10: 549-560.

4. Unhealthy sleep-related behaviors--12 States, 2009. MMWR Morbidity and mortality weekly report 2011; 60: 233-238.

5. Perceived insufficient rest or sleep among adults - United States, 2008. MMWR Morbidity and mortality weekly report 2009; 58: 1175-1179.

6. Hysing M, Pallesen S, Stormark KM, Lundervold AJ, Sivertsen B. Sleep patterns and insomnia among adolescents: a population-based study. Journal of sleep research 2013; 22: 549-556.

7. Shochat T, Cohen-Zion M, Tzischinsky O. Functional consequences of inadequate sleep in adolescents: a systematic review. Sleep medicine reviews 2014; 18: 75-87.

8. $\quad$ Sleep Disorders and Sleep Deprivation: An Unmet Public Health Problem. National Academy of Sciences.: Washington DC, 2006.

9. Killgore WD. Effects of sleep deprivation on cognition. Prog Brain Res 2010; 185: 105-129.

10. Wulff K, Gatti S, Wettstein JG, Foster RG. Sleep and circadian rhythm disruption in psychiatric and neurodegenerative disease. Nature reviews Neuroscience 2010; 11: 589-599.

11. McClung CA. How might circadian rhythms control mood? Let me count the ways. Biol Psychiatry 2013; 74: 242-249.

12. Benedetti F, Colombo C. Sleep deprivation in mood disorders. Neuropsychobiology 2011; 64: 141-151.

13. Wu JC, Bunney WE. The biological basis of an antidepressant response to sleep deprivation and relapse: review and hypothesis. Am J Psychiatry 1990; 147: 14-21. 
14. Borbely AA. A two process model of sleep regulation. Human neurobiology 1982; 1: 195-204.

15. Daan S, Beersma DG, Borbely AA. Timing of human sleep: recovery process gated by a circadian pacemaker. The American journal of physiology 1984; 246: R161-183.

16. Moore RY. Suprachiasmatic nucleus in sleep-wake regulation. Sleep medicine 2007; 8 Suppl 3: 27-33.

17. Tononi G, Cirelli C. Sleep function and synaptic homeostasis. Sleep medicine reviews 2006; 10: 49-62.

18. Cirelli C. Sleep and synaptic changes. Curr Opin Neurobiol 2013; 23: 841-846.

19. Vyazovskiy VV, Cirelli C, Pfister-Genskow M, Faraguna U, Tononi G. Molecular and electrophysiological evidence for net synaptic potentiation in wake and depression in sleep. Nat Neurosci 2008; 11: 200-208.

20. Liu ZW, Faraguna U, Cirelli C, Tononi G, Gao XB. Direct evidence for wake-related increases and sleep-related decreases in synaptic strength in rodent cortex. The Journal of neuroscience : the official journal of the Society for Neuroscience 2010; 30: 8671-8675.

21. Maret S, Faraguna U, Nelson AB, Cirelli C, Tononi G. Sleep and waking modulate spine turnover in the adolescent mouse cortex. Nature neuroscience 2011; 14: 1418-1420.

22. Gilestro GF, Tononi G, Cirelli C. Widespread changes in synaptic markers as a function of sleep and wakefulness in Drosophila. Science (New York, NY) 2009; 324: 109-112.

23. Bushey D, Tononi G, Cirelli C. Sleep and synaptic homeostasis: structural evidence in Drosophila. Science (New York, NY) 2011; 332: 1576-1581.

24. Huber R, Maki H, Rosanova M, Casarotto S, Canali P, Casali AG et al. Human cortical excitability increases with time awake. Cereb Cortex 2013; 23: 332-338.

25. Hung CS, Sarasso S, Ferrarelli F, Riedner B, Ghilardi MF, Cirelli C et al. Local experience-dependent changes in the wake EEG after prolonged wakefulness. Sleep 2013; 36: 59-72.

26. Harris JJ, Jolivet R, Attwell D. Synaptic energy use and supply. Neuron 2012; 75: 762 777. 
27. Raichle ME, Mintun MA. Brain work and brain imaging. Annual review of neuroscience 2006; 29: 449-476.

28. Tononi G, Cirelli C. Sleep and the price of plasticity: from synaptic and cellular homeostasis to memory consolidation and integration. Neuron 2014; 81: 12-34.

29. Kuboyama T, Hori A, Sato T, Mikami T, Yamaki T, Ueda S. Changes in cerebral blood flow velocity in healthy young men during overnight sleep and while awake. Electroencephalography and clinical neurophysiology 1997; 102: 125-131.

30. Braun AR, Balkin TJ, Wesenten NJ, Carson RE, Varga M, Baldwin P et al. Regional cerebral blood flow throughout the sleep-wake cycle. An H2(15)O PET study. Brain : a journal of neurology 1997; 120 ( Pt 7): 1173-1197.

31. Hodkinson DJ, O'Daly O, Zunszain PA, Pariante CM, Lazurenko V, Zelaya FO et al. Circadian and homeostatic modulation of functional connectivity and regional cerebral blood flow in humans under normal entrained conditions. Journal of cerebral blood flow and metabolism : official journal of the International Society of Cerebral Blood Flow and Metabolism 2014; 34: 1493-1499.

32. Shannon BJ, Dosenbach RA, Su Y, Vlassenko AG, Larson-Prior LJ, Nolan TS et al. Morning-evening variation in human brain metabolism and memory circuits. $J$ Neurophysiol 2013; 109: 1444-1456.

33. Alsop DC, Detre JA, Golay X, Gunther M, Hendrikse J, Hernandez-Garcia L et al. Recommended implementation of arterial spin-labeled perfusion MRI for clinical applications: A consensus of the ISMRM perfusion study group and the European consortium for ASL in dementia. Magnetic resonance in medicine 2015; 73: 102-116.

34. Elvsashagen T, Zak N, Norbom LB, Pedersen PO, Quraishi SH, Bjornerud A et al. Evidence for cortical structural plasticity in humans after a day of waking and sleep deprivation. NeuroImage 2017; 156: 214-223.

35. Kaufmann T, Elvsashagen T, Alnaes D, Zak N, Pedersen PO, Norbom LB et al. The brain functional connectome is robustly altered by lack of sleep. NeuroImage 2016; 127: 324-332.

36. Elvsashagen T, Norbom LB, Pedersen PO, Quraishi SH, Bjornerud A, Malt UF et al. Widespread changes in white matter microstructure after a day of waking and sleep deprivation. PloS one 2015; 10: e0127351. 
37. Horne JA, Ostberg O. A self-assessment questionnaire to determine morningnesseveningness in human circadian rhythms. International journal of chronobiology 1976; 4: 97-110.

38. Johns MW. A new method for measuring daytime sleepiness: the Epworth sleepiness scale. Sleep 1991; 14: 540-545.

39. Buysse DJ, Reynolds CF, 3rd, Monk TH, Berman SR, Kupfer DJ. The Pittsburgh Sleep Quality Index: a new instrument for psychiatric practice and research. Psychiatry research 1989; 28: 193-213.

40. Akerstedt T, Gillberg M. Subjective and objective sleepiness in the active individual. The International journal of neuroscience 1990; 52: 29-37.

41. Fan J, McCandliss BD, Sommer T, Raz A, Posner MI. Testing the efficiency and independence of attentional networks. Journal of cognitive neuroscience 2002; 14: 340-347.

42. Hales PW, Kirkham FJ, Clark CA. A general model to calculate the spin-lattice (T1) relaxation time of blood, accounting for haematocrit, oxygen saturation and magnetic field strength. Journal of cerebral blood flow and metabolism : official journal of the International Society of Cerebral Blood Flow and Metabolism 2016; 36: 370-374.

43. Dai W, Garcia D, de Bazelaire C, Alsop DC. Continuous flow-driven inversion for arterial spin labeling using pulsed radio frequency and gradient fields. Magnetic resonance in medicine 2008; 60: 1488-1497.

44. Wu WC, Fernandez-Seara M, Detre JA, Wehrli FW, Wang J. A theoretical and experimental investigation of the tagging efficiency of pseudocontinuous arterial spin labeling. Magnetic resonance in medicine 2007; 58: 1020-1027.

45. Mutsaerts H, Petr J, Thomas DL, De Vita E, Cash DM, van Osch MJP et al. Comparison of arterial spin labeling registration strategies in the multi-center GENetic frontotemporal dementia initiative (GENFI). Journal of magnetic resonance imaging : JMRI 2018; 47: 131-140.

46. ExploreASL: image processing toolbox for multi-center arterial spin labeling population analyses. Proceedings of the 34th Annual Scientific Meeting of European Society for Magnetic Resonance in Medicine and Biology2017; Barcelona, Spain. 
47. Wang Z, Aguirre GK, Rao H, Wang J, Fernandez-Seara MA, Childress AR et al. Empirical optimization of ASL data analysis using an ASL data processing toolbox: ASLtbx. Magnetic resonance imaging 2008; 26: 261-269.

48. Shirzadi Z, Crane DE, Robertson AD, Maralani PJ. Automated removal of spurious intermediate cerebral blood flow volumes improves image quality among older patients: A clinical arterial spin labeling investigation. 2015; 42: 1377-1385.

49. Ashburner J. A fast diffeomorphic image registration algorithm. NeuroImage 2007; 38: 95-113.

50. Hayley AC, Skogen JC, Overland S, Wold B, Williams LJ, Kennedy GA et al. Trajectories and stability of self-reported short sleep duration from adolescence to adulthood. Journal of sleep research 2015; 24: 621-628.

51. Boyle PJ, Scott JC, Krentz AJ, Nagy RJ, Comstock E, Hoffman C. Diminished brain glucose metabolism is a significant determinant for falling rates of systemic glucose utilization during sleep in normal humans. The Journal of clinical investigation 1994; 93: 529-535.

52. Bartlett EJ, Brodie JD, Wolf AP, Christman DR, Laska E, Meissner M. Reproducibility of cerebral glucose metabolic measurements in resting human subjects. Journal of cerebral blood flow and metabolism : official journal of the International Society of Cerebral Blood Flow and Metabolism 1988; 8: 502-512.

53. Buysse DJ, Nofzinger EA, Germain A, Meltzer CC, Wood A, Ombao H et al. Regional brain glucose metabolism during morning and evening wakefulness in humans: preliminary findings. Sleep 2004; 27: 1245-1254.

54. Raichle ME, MacLeod AM, Snyder AZ, Powers WJ, Gusnard DA, Shulman GL. A default mode of brain function. Proceedings of the National Academy of Sciences of the United States of America 2001; 98: 676-682.

55. Colavito V, Tesoriero C, Wirtu AT, Grassi-Zucconi G, Bentivoglio M. Limbic thalamus and state-dependent behavior: The paraventricular nucleus of the thalamic midline as a node in circadian timing and sleep/wake-regulatory networks. Neuroscience and biobehavioral reviews 2015; 54: 3-17.

56. Phelps EA, LeDoux JE. Contributions of the amygdala to emotion processing: from animal models to human behavior. Neuron 2005; 48: 175-187. 
57. Sigurdsson T, Doyere V, Cain CK, LeDoux JE. Long-term potentiation in the amygdala: a cellular mechanism of fear learning and memory. Neuropharmacology 2007; 52: 215-227.

58. Abel T, Havekes R, Saletin JM, Walker MP. Sleep, plasticity and memory from molecules to whole-brain networks. Current biology: CB 2013; 23: R774-788.

59. Walker MP, Stickgold R. Sleep-dependent learning and memory consolidation. Neuron 2004; 44: 121-133.

60. Patrick GTW, Gilbert JA. Studies from the psychological laboratory of the University of Iowa. On the effects of loss of sleep. Psychol Rev 1896; 3: 469-483.

61. Mangold R, Sokoloff L, Conner E, Kleinerman J, Therman PO, Kety SS. The effects of sleep and lack of sleep on the cerebral circulation and metabolism of normal young men. The Journal of clinical investigation 1955; 34: 1092-1100.

62. Thomas M, Sing H, Belenky G, Holcomb H, Mayberg H, Dannals R et al. Neural basis of alertness and cognitive performance impairments during sleepiness. I. Effects of 24 $\mathrm{h}$ of sleep deprivation on waking human regional brain activity. Journal of sleep research 2000; 9: 335-352.

63. Wu JC, Gillin JC, Buchsbaum MS, Hershey T, Hazlett E, Sicotte N et al. The effect of sleep deprivation on cerebral glucose metabolic rate in normal humans assessed with positron emission tomography. Sleep 1991; 14: 155-162.

64. Wu JC, Gillin JC, Buchsbaum MS, Chen P, Keator DB, Khosla Wu N et al. Frontal lobe metabolic decreases with sleep deprivation not totally reversed by recovery sleep. Neuropsychopharmacology : official publication of the American College of Neuropsychopharmacology 2006; 31: 2783-2792.

65. Poudel GR, Innes CR, Jones RD. Cerebral perfusion differences between drowsy and nondrowsy individuals after acute sleep restriction. Sleep 2012; 35: 1085-1096.

66. Asplund CL, Chee MW. Time-on-task and sleep deprivation effects are evidenced in overlapping brain areas. NeuroImage 2013; 82: 326-335.

67. Sridharan D, Levitin DJ, Menon V. A critical role for the right fronto-insular cortex in switching between central-executive and default-mode networks. Proceedings of the National Academy of Sciences of the United States of America 2008; 105: 1256912574. 
68. Krause AJ, Simon EB, Mander BA, Greer SM, Saletin JM, Goldstein-Piekarski AN et al. The sleep-deprived human brain. Nature reviews Neuroscience 2017; 18: 404-418.

69. Chen MC, Chiang WY, Yugay T, Patxot M, Ozcivit IB, Hu K et al. Anterior Insula Regulates Multiscale Temporal Organization of Sleep and Wake Activity. Journal of biological rhythms 2016; 31: 182-193.

70. Gorgoni M, Ferlazzo F, Moroni F, D'Atri A, Donarelli S, Fanelli S et al. Sleep deprivation affects somatosensory cortex excitability as tested through median nerve stimulation. Brain stimulation 2014; 7: 732-739.

71. Terney D, Beniczky S, Varga ET, Keri S, Nagy HG, Vecsei L. The effect of sleep deprivation on median nerve somatosensory evoked potentials. Neuroscience letters 2005; 383: 82-86.

72. De Gennaro L, Marzano C, Veniero D, Moroni F, Fratello F, Curcio G et al. Neurophysiological correlates of sleepiness: a combined TMS and EEG study. NeuroImage 2007; 36: 1277-1287.

73. Scalise A, Desiato MT, Gigli GL, Romigi A, Tombini M, Marciani MG et al. Increasing cortical excitability: a possible explanation for the proconvulsant role of sleep deprivation. Sleep 2006; 29: 1595-1598.

74. Chee MW, Goh CS, Namburi P, Parimal S, Seidl KN, Kastner S. Effects of sleep deprivation on cortical activation during directed attention in the absence and presence of visual stimuli. NeuroImage 2011; 58: 595-604.

75. Chee MW, Tan JC. Lapsing when sleep deprived: neural activation characteristics of resistant and vulnerable individuals. NeuroImage 2010; 51: 835-843.

76. Clement P, Mutsaerts HJ, Vaclavu L, Ghariq E, Pizzini FB, Smits M et al. Variability of physiological brain perfusion in healthy subjects - A systematic review of modifiers. Considerations for multi-center ASL studies. Journal of cerebral blood flow and metabolism : official journal of the International Society of Cerebral Blood Flow and Metabolism 2017; 271678x17702156.

77. Nakamura K, Brown RA, Narayanan S, Collins DL, Arnold DL. Diurnal fluctuations in brain volume: Statistical analyses of MRI from large populations. NeuroImage 2015; 118: $126-132$.

78. Trefler A, Sadeghi N, Thomas AG, Pierpaoli C, Baker CI, Thomas C. Impact of time-ofday on brain morphometric measures derived from T-weighted magnetic resonance imaging. NeuroImage 2016; 133: 41-52. 
79. Bernardi G, Cecchetti L, Siclari F, Buchmann A, Yu X, Handjaras G et al. Sleep reverts changes in human gray and white matter caused by wake-dependent training. NeuroImage 2016; 129: 367-377. 


\section{TABLES}

\begin{tabular}{|c|c|c|c|}
\hline Characteristics & $\begin{array}{l}\text { All participants } \\
(n=38)\end{array}$ & $\begin{array}{l}\text { Sleep deprived } \\
(n=19)\end{array}$ & $\begin{array}{l}\text { Sleep } \\
(n=19)\end{array}$ \\
\hline Age (years) & $22.1 \pm 2.5$ & $21.5 \pm 2.7$ & $22.7 \pm 2.2$ \\
\hline Handedness (right) & $100 \%$ & $100 \%$ & $100 \%$ \\
\hline ESS (0-24) & $7.3 \pm 2.4$ & $7.2 \pm 2.6$ & $7.3 \pm 2.4$ \\
\hline PSQIa $(0-24)$ & $4.2 \pm 2.1$ & $4.0 \pm 1.7$ & $4.6 \pm 2.5$ \\
\hline $\mathrm{HOME}^{\mathrm{b}}(16-86)$ & $48.8 \pm 8.7$ & $49.0 \pm 9.1$ & $48.6 \pm 8.4$ \\
\hline Daily sleep week be & & & \\
\hline (h:min) & $7 \mathrm{~h} 30 \pm 0 \mathrm{~h} 50$ & $7 \mathrm{~h} 35 \pm 0 \mathrm{~h} 50$ & $7 \mathrm{~h} 25 \pm 1 \mathrm{~h}$ \\
\hline Daily sleep month be & & & \\
\hline (h:min) & $7 \mathrm{~h} 35 \pm 0 \mathrm{~h} 50$ & $7 \mathrm{~h} 35 \pm 0 \mathrm{~h} 50$ & $7 \mathrm{~h} 35 \pm 0 \mathrm{~h} 50$ \\
\hline Sleep before TP1 (h:min) & $6 \mathrm{~h} 45 \pm 1 \mathrm{~h} 10$ & $6 \mathrm{~h} 55 \pm 1 \mathrm{~h} 25$ & $6 h 35 \pm 1 h$ \\
\hline Sleep before TP3 ${ }^{\mathrm{b}}$ (h:min) & $\mathrm{n} / \mathrm{a}$ & 0 & $6 \mathrm{~h} 10 \pm 0 \mathrm{~h} 55$ \\
\hline
\end{tabular}

Table 1. Sample characteristics and hours of sleep. ESS = Epworth Sleepiness Score, HOME = HorneÖstberg Morningness-Eveningness questionnaire, PSQI = Pittsburgh Sleep Quality Index, n/a = not applicable, TP = time point. ${ }^{a}$ Missing for one participant of the sleep group. ${ }^{b}$ Missing for one participant of the sleep deprivation group 


\begin{tabular}{|c|c|c|c|c|c|c|}
\hline & \multirow[b]{2}{*}{ Hct (\%) } & \multirow[b]{2}{*}{$\mathrm{T} 1_{\mathrm{b}}(\mathrm{ms})$} & & \\
\hline & & & $\operatorname{Hct}(\%)$ & $\mathrm{T} 1_{\mathrm{b}}(\mathrm{ms})$ & Hct $(\%)$ & $\mathrm{T} 1_{\mathrm{b}}(\mathrm{ms})$ \\
\hline All participants $(\mathrm{n}=38)$ & $47.1 \pm 2.8$ & $1700 \pm 34$ & $45.0 \pm 2.5$ & $1729 \pm 31$ & $46.1 \pm 2.7$ & $1714 \pm 33$ \\
\hline Sleep $(n=19)$ & $46.5 \pm 3.0$ & $1709 \pm 33$ & $44.7 \pm 2.3$ & $1732 \pm 30$ & $46.1 \pm 2.5$ & $1714 \pm 31$ \\
\hline Sleep deprivation $(n=19)$ & $47.6 \pm 2.9$ & $1696 \pm 35$ & $45.2 \pm 2.7$ & $1726 \pm 33$ & $46.2 \pm 2.9$ & $1714 \pm 36$ \\
\hline
\end{tabular}

Table 2. Average hematocrit values (Hct) at each time point and corresponding calculated longitudinal relaxation rate of blood $\left(\mathrm{T}_{\mathrm{b}}\right)$, used in the quantification of cerebral blood flow. $\mathrm{TP}=$ time point.

\begin{tabular}{|c|c|c|c|c|c|}
\hline Cluster & $\begin{array}{c}\text { Cluster } \\
\text { volume } \\
(\mathrm{mL})\end{array}$ & $\begin{array}{c}\text { CBF } \\
\text { change } \\
(\%)^{*}\end{array}$ & $\begin{array}{l}\text { Peak } t \\
\text { score }\end{array}$ & $\begin{array}{l}\text { Peak MNI } \\
\text { coordinates (mm, } \\
\text { for } X, Y, Z)\end{array}$ & Main brain regions in cluster \\
\hline I & 4.8 & 11.0 & 7.6 & $-19.5,-34.5,10.5$ & $\begin{array}{l}\text { L hippocampus, L amygdala, B } \\
\text { thalamus }\end{array}$ \\
\hline II & 4.3 & 9.2 & 5.5 & $-46.5,-13.5,39.0$ & L precentral gyrus, L postcentral gyrus \\
\hline III & 2.8 & 7.5 & 6.1 & $21.0,-34.5,9.0$ & $\begin{array}{c}\text { R hippocampus, } \mathrm{R} \text { thalamus, } \mathrm{R} \\
\text { amygdala, R lingual gyrus }\end{array}$ \\
\hline IV & 2.8 & 8.2 & 5.1 & $51.0,-12.0,33.0$ & R precentral gyrus, $R$ postcentral gyrus \\
\hline
\end{tabular}

Table 3. Clusters with significant rCBF increases after a day of wake (TP1 versus TP2; $n=38$ ). $B=$ bilateral, $\mathrm{L}=$ left, $\mathrm{R}=$ right. $\mathrm{MNI}=$ Montreal Neurological Institute, $\mathrm{rCBF}=$ resting cerebral blood flow, TP = time point. *Positive value indicates increase from TP1 to TP2. 


\begin{tabular}{|c|c|c|c|c|c|c|}
\hline \multirow[b]{2}{*}{ Cluster } & \multirow[b]{2}{*}{$\begin{array}{c}\text { Cluster } \\
\text { volume } \\
(\mathrm{mL})\end{array}$} & \multicolumn{2}{|c|}{ CBF change $(\%) *$} & \multirow[b]{2}{*}{$\begin{array}{l}\text { Peak } \\
t \\
\text { score }\end{array}$} & \multirow[b]{2}{*}{$\begin{array}{c}\text { Peak MNI } \\
\text { coordinates } \\
(\mathrm{mm}, \text { for } \mathrm{X}, \mathrm{Y}, \\
\mathrm{Z})\end{array}$} & \multirow[b]{2}{*}{ Main brain regions in cluster } \\
\hline & & $\begin{array}{c}\text { Sleep } \\
\text { deprived } \\
\text { group }\end{array}$ & $\begin{array}{l}\text { Sleep } \\
\text { group }\end{array}$ & & & \\
\hline
\end{tabular}

A) Cluster with main effect of time from TP2 to TP3:

\begin{tabular}{|l|l|l|l|l|l|l} 
I & 12.1 & -9.2 & -8.2 & 6.5 & $12.0,-27.0,13.5$ & B thalamus, B hippocampus \\
\hline
\end{tabular}

B) Clusters with significant group $x$ time interaction effects from TP2 to TP3:

\begin{tabular}{|c|c|c|c|c|c|c|}
\hline I & 30.7 & 9.8 & -8.8 & 6.5 & $33.0,-79.5,-10.5$ & $\begin{array}{c}\text { R lingual gyrus, R occipital fusiform } \\
\text { gyrus, R lateral occipital cortex, R } \\
\text { occipital pole, L occipital pole, } \mathrm{R} \\
\text { temporal occipital fusiform cortex, } \mathrm{L} \\
\text { cuneal cortex, B lateral occipital } \\
\text { cortex, R cuneal cortex, L } \\
\text { intracalcarine cortex, } \mathrm{R} \\
\text { supracalcarine cortex, R inferior } \\
\text { temporal gyrus }\end{array}$ \\
\hline II & 11.8 & 10.3 & -8.7 & & $-33.0,-81.0,-15.0$ & $\begin{array}{c}\text { L occipital fusiform gyrus, L lingual } \\
\text { gyrus, L occipital cortex, L occipital } \\
\text { pole, L temporal occipital fusiform } \\
\text { cortex }\end{array}$ \\
\hline III & 1.9 & 7.5 & -7.1 & & $-37.5,-40.5,25.5$ & $\begin{array}{c}\text { L temporal occipital fusiform cortex, L } \\
\text { temporal fusiform cortex }\end{array}$ \\
\hline IV & 1.7 & 8.2 & -8.1 & 6.2 & $36.0,0.0,-10.5$ & $\begin{array}{c}\text { R insular cortex, R central opercular } \\
\text { cortex }\end{array}$ \\
\hline V & 1.5 & 9.4 & -6.6 & 5.7 & $-37.5,4.5,-7.5$ & L insular cortex, L planum polare \\
\hline
\end{tabular}

Table 4. A) Cluster with main effect of time from TP2 to TP3 (n=38). B) Clusters with significant group $\mathrm{x}$ time interaction effects from TP2 to TP3, with CBF increases in sleep deprived individuals and decreases in sleepers $(\mathrm{n}=38) . \mathrm{B}=$ bilateral, $\mathrm{L}=$ left, $\mathrm{R}=$ right. $\mathrm{MNI}=$ Montreal Neurological Institute, $\mathrm{rCBF}=$ resting cerebral blood flow, $\mathrm{TP}=$ time point. ${ }^{*}$ Positive and negative values indicate increases and decreases from TP2 to TP3, respectively. 


\begin{tabular}{|c|c|c|c|c|c|c|}
\hline \multirow[b]{2}{*}{ Cluster } & \multirow{2}{*}{$\begin{array}{c}\text { Cluster } \\
\text { volume } \\
\text { (mL) }\end{array}$} & \multicolumn{2}{|c|}{ CBF change $(\%)^{*}$} & \multirow{2}{*}{$\begin{array}{l}\text { Peak } \\
t \\
\text { score }\end{array}$} & \multirow{2}{*}{$\begin{array}{c}\text { Peak MNI } \\
\text { coordinates } \\
(\mathrm{mm}, \text { for } \mathrm{X}, \mathrm{Y}, \mathrm{Z})\end{array}$} & \multirow[b]{2}{*}{ Main brain regions in cluster } \\
\hline & & $\begin{array}{c}\text { Sleep } \\
\text { deprived } \\
\text { group }\end{array}$ & $\begin{array}{l}\text { Sleep } \\
\text { group }\end{array}$ & & & \\
\hline
\end{tabular}

A) Cluster with main effect of time from TP1 to TP3:

\begin{tabular}{|c|c|c|c|c|c|c|}
\hline I & 4.1 & 6.3 & -3.2 & 5.18 & $-40.5,-33.0,57.0$ & $\begin{array}{c}\text { L postcentral gyrus, L precentral } \\
\text { gyrus }\end{array}$ \\
\hline II & 3.9 & 7.7 & -4.6 & 5.78 & $-13.5,-45.0,69.0$ & $\begin{array}{c}\text { L postcentral gyrus, L superior } \\
\text { parietal lobule, L precentral gyrus, L } \\
\text { lateral occipital cortex, L } \\
\text { juxtapositional lobule cortex, L } \\
\text { precuneous cortex }\end{array}$ \\
\hline III & 1.5 & -11.0 & -4.1 & 4.9 & $10.5,-12.0,9.0$ & R thalamus \\
\hline IV & 1.4 & 6.6 & -4.7 & 5.1 & $34.5,-27.0,61.5$ & R postcentral gyrus, R precentral \\
gyrus
\end{tabular}

B) Clusters with significant group $x$ time interaction effects from TP1 to TP3:

\begin{tabular}{|c|c|c|c|c|c|c|}
\hline I & 9.4 & 14.0 & -5.4 & 6.7 & $51.0,-69.0,-3.0$ & $\begin{array}{c}\text { R lateral occipital cortex, R occipital } \\
\text { fusiform gyrus, R lingual gyrus, R } \\
\text { temporal occipital fusiform cortex, R } \\
\text { occipital pole }\end{array}$ \\
\hline II & 3.7 & 14.6 & -4.2 & 6.8 & $-33.0,-81.0,-16.5$ & $\begin{array}{c}\text { L occipital fusiform gyrus, L lingual } \\
\text { gyrus, L lateral occipital cortex }\end{array}$ \\
\hline III & 3.3 & 13.3 & -3.8 & 6.0 & $3.0,15.0,28.5$ & $\begin{array}{c}\text { B anterior cingulate gyrus, B } \\
\text { juxtapositional lobule }\end{array}$ \\
\hline IV & 2.2 & 13.7 & -5.3 & 5.7 & $-37.5,-4.5,-4.5$ & L insular cortex, L planum polare \\
\hline V & 1.8 & 11.1 & -5.8 & 6.6 & $37.5,-1.5,-10.5$ & R insular cortex \\
\hline
\end{tabular}

Table 5. A) Clusters with main effects of time from TP1 to TP3 (n=38). B) Clusters with significant group $\mathrm{x}$ time interaction effects from TP1 to TP3, with CBF increases in sleep deprived individuals and decreases in sleepers $(\mathrm{n}=38) . \mathrm{B}=$ bilateral, $\mathrm{L}=$ left, $\mathrm{R}=$ right. $\mathrm{MNI}=$ Montreal Neurological Institute, $\mathrm{rCBF}=$ resting cerebral blood flow, $\mathrm{TP}=$ time point. ${ }^{*}$ Positive and negative values indicate increases and decreases from TP2 to TP3, respectively. 


\section{FIGURE LEGENDS}

Figure 1. The participants underwent magnetic resonance imaging in the morning after a night of regular sleep in their homes (time point (TP) 1), after approximately 14 hours of waking (TP2), and then 9-10 hours later (TP3), either after a night of sleep at home or after a night of total sleep deprivation (A). Sleep deprivation was associated with significant increases in intra-individual variation in reaction time (B) and mean reaction time (C) of the attention network task and in Karolinska Sleepiness Scale (D). CoV $=$ coefficient of variation, $\mathrm{MRI}=$ magnetic resonance imaging.

Figure 2. Resting cerebral blood flow (rCBF) changes after a day of wake (time point (TP1) versus TP2) across all 38 participants, shown in $\mathrm{mL} / 100 \mathrm{~g} / \mathrm{min}$. Only significant voxels are shown $-p<0.001$ primary ( $\mathrm{k}=395$ voxels) and a $p<0.05$ FWE cluster-forming threshold overlaid over the population-average anatomical 3D T1 image. There were no areas with significant $\mathrm{rCBF}$ decreases. First slice (upper left corner) corresponds to MNI $\mathrm{z}=-22 \mathrm{~mm}$, each increment being $6 \mathrm{~mm}$, ending at MNI z=68 mm (lower right corner). The slices are displayed in radiological (left is right) convention. MNI = Montreal Neurological Institute.

Figure 3. Resting cerebral blood flow (rCBF) changes between time point (TP) 2 and TP3. a) shows clusters with main effects of time on $\mathrm{rCBF}$ and b) shows clusters with significant group $\mathrm{x}$ time interaction, shown in $\mathrm{mL} / 100 \mathrm{~g} / \mathrm{min}$. Only significant voxels are shown $p<0.001$ primary ( $\mathrm{k}=440$ for both) and $p<0.05$ FWE secondary cluster-forming threshold overlaid over the population-average anatomical 3D T1 image. First slice (upper left corner) 
corresponds to MNI z=-22 mm, each increment being $6 \mathrm{~mm}$, ending at MNI z=68 mm (lower right corner). The slices are displayed in radiological (left is right) convention. $\mathrm{MNI}=$ Montreal Neurological Institute.

Figure 4. Resting cerebral blood flow (rCBF) changes between time point (TP) 2 versus TP3 for a) the sleep group ( $n=19$, left) and b) deprived group ( $n=19$, right), shown in $\mathrm{mL} / 100 \mathrm{~g} / \mathrm{min}$. Only significant voxels are shown $-p<0.001$ primary $(\mathrm{k}=381$ and $\mathrm{k}=390$ for a and $\mathrm{b}$, respectively) and $p<0.05$ FWE secondary cluster-forming threshold - overlaid over the population-average anatomical 3D T1 image. First slice (upper left corner) corresponds to $\mathrm{MNI} z=-22 \mathrm{~mm}$, each increment being $6 \mathrm{~mm}$, ending at MNI $\mathrm{z}=68 \mathrm{~mm}$ (lower right corner). The slices are displayed in radiological (left is right) convention. MNI = Montreal Neurological Institute.

Figure 5. Conjunction analysis shows the contrasts of Figure 2 (blue), Figure 4a (red) and their overlap (yellow). First slice (upper left corner) corresponds to MNI $\mathrm{z}=-22 \mathrm{~mm}$, each increment being $6 \mathrm{~mm}$, ending at $\mathrm{MNI} \mathrm{z}=68 \mathrm{~mm}$ (lower right corner). The slices are displayed in radiological (left is right) convention. MNI = Montreal Neurological Institute .

Figure 6. Resting cerebral blood flow (rCBF) changes between time point (TP) 1 and TP3. a) shows clusters with main effects of time on $\mathrm{rCBF}$ and b) shows clusters with significant group $\mathrm{x}$ time interaction, shown in $\mathrm{mL} / 100 \mathrm{~g} / \mathrm{min}$. Only significant voxels are shown $p<0.001$ primary ( $\mathrm{k}=440$ for both) and $p<0.05 \mathrm{FWE}$ secondary cluster-forming threshold - 
overlaid over the population-average anatomical 3D T1 image. First slice (upper left corner) corresponds to MNI z=-22 mm, each increment being $6 \mathrm{~mm}$, ending at MNI z=68 $\mathrm{mm}$ (lower right corner). The slices are displayed in radiological (left is right) convention. $\mathrm{MNI}=$ Montreal Neurological Institute.

Figure 7. Resting cerebral blood flow (rCBF) changes after approximately 23 hours of sleep deprivation (time point (TP1) versus TP3) in the sleep deprivation group ( $n=19)$, shown in $\mathrm{mL} / 100 \mathrm{~g} / \mathrm{min}$. Only significant voxels are shown $-p<0.001$ primary $(\mathrm{k}=283)$ and $p<0.05$ FWE secondary cluster-forming threshold - overlaid over the population-average anatomical 3D T1 image. First slice (upper left corner) corresponds to MNI $\mathrm{z}=-22 \mathrm{~mm}$, each increment being $6 \mathrm{~mm}$, ending at $\mathrm{MNI} \mathrm{z}=68 \mathrm{~mm}$ (lower right corner). The slices are displayed in radiological (left is right) convention. MNI = Montreal Neurological Institute. There were no rCBF changes between TP1 and TP3 for the sleep group ( $n=19$, data not shown). 


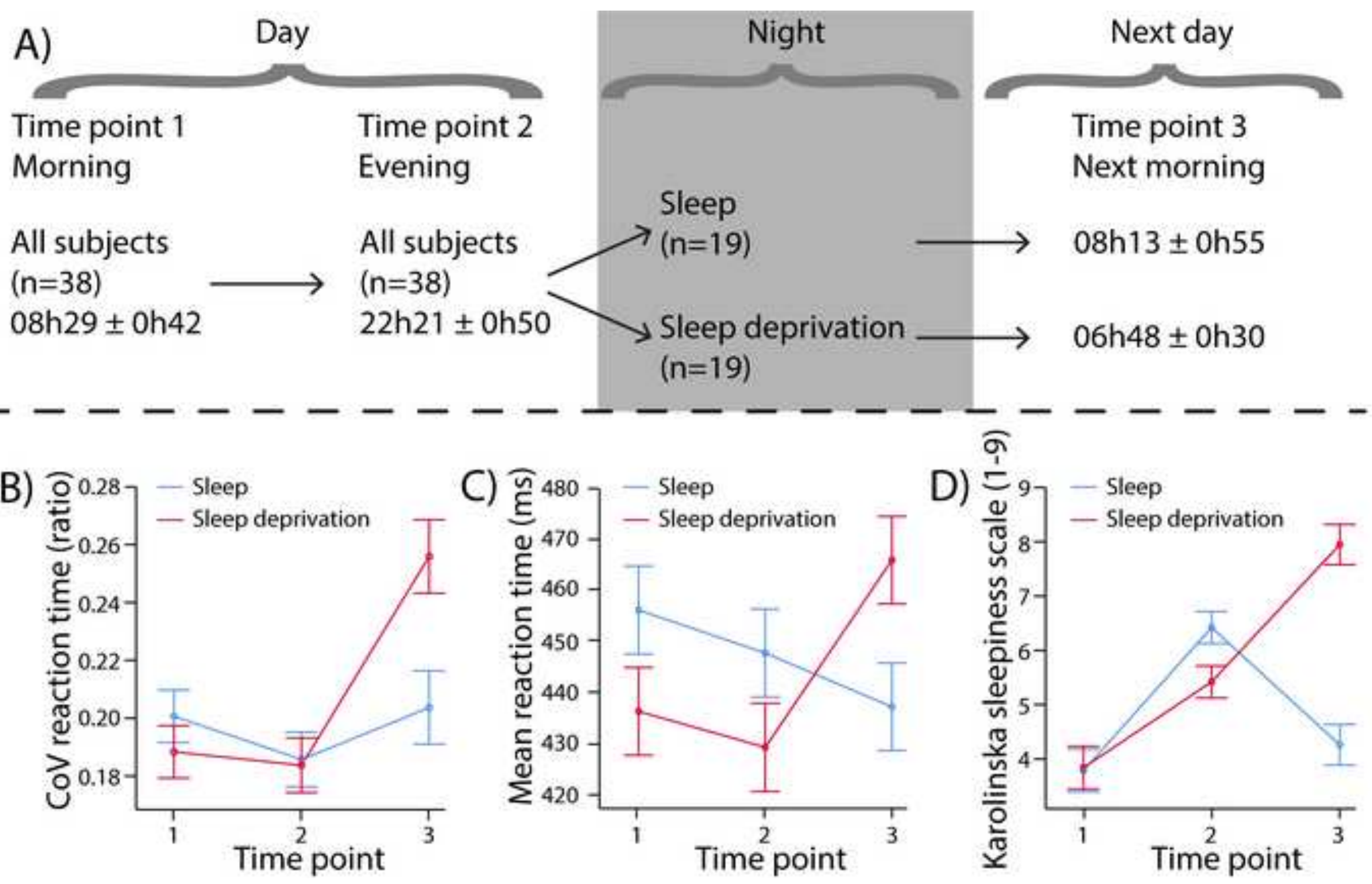


Click here to download high resolution image

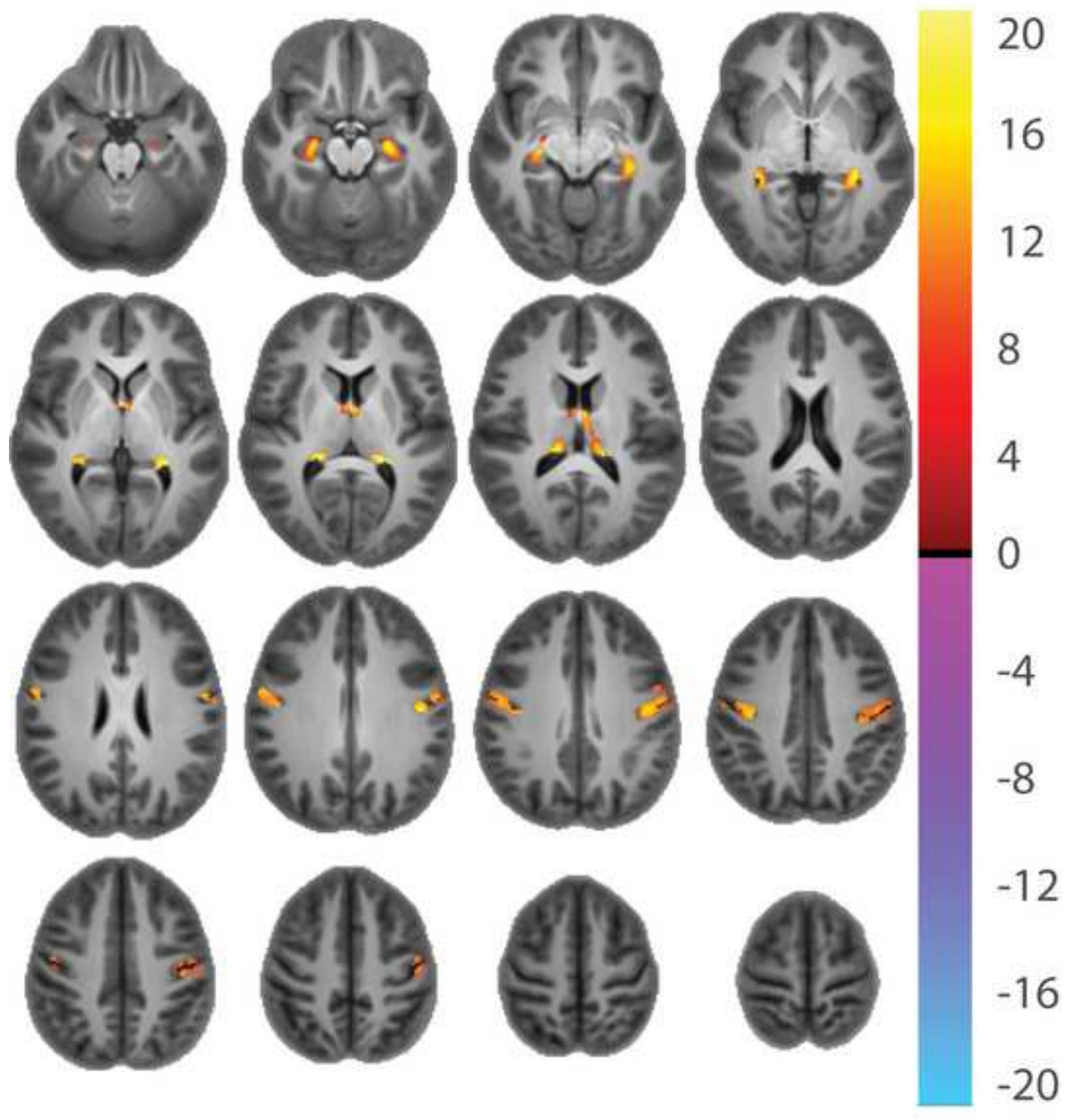


Main effects

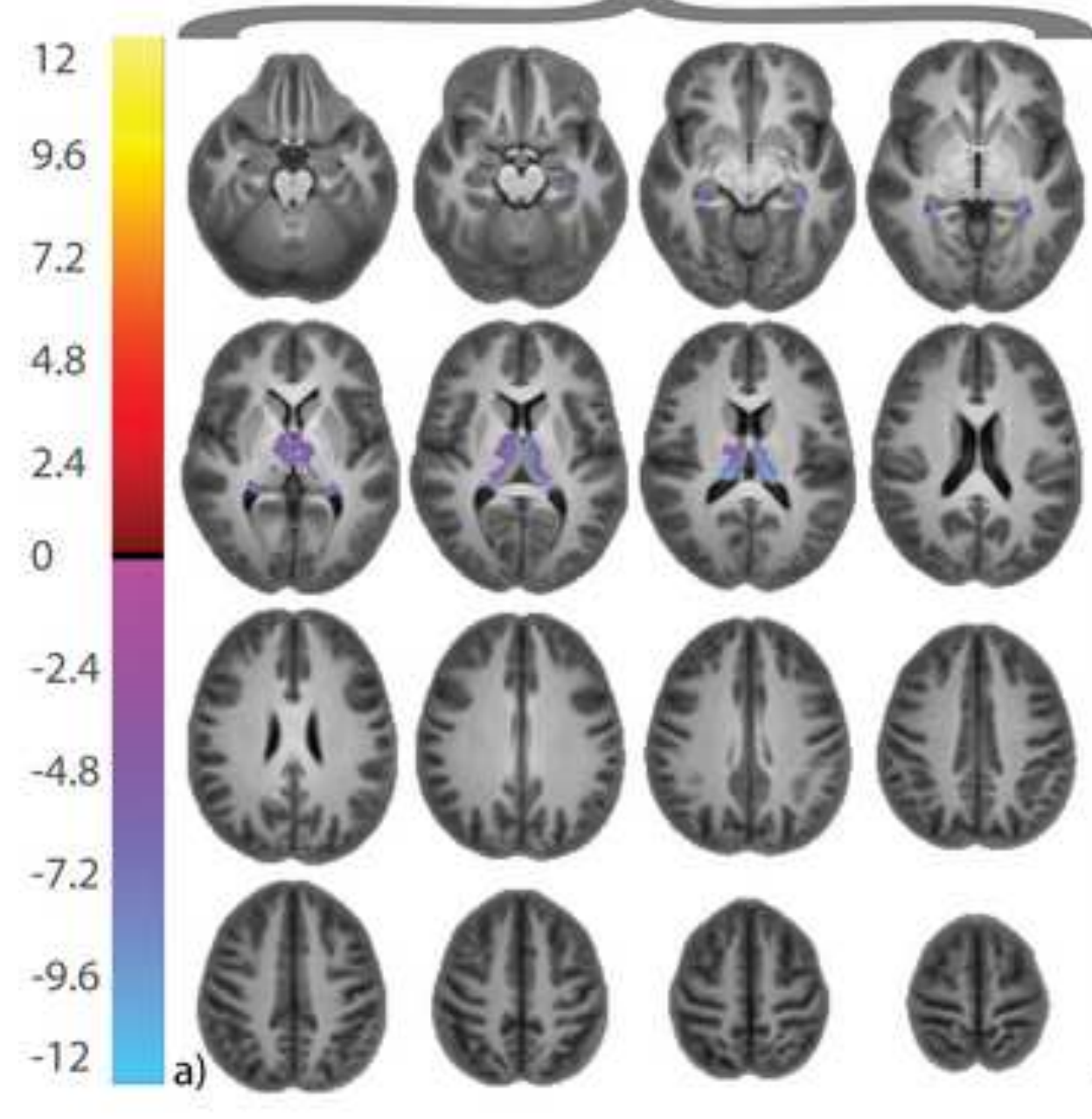

Group $\times$ time point interaction effects

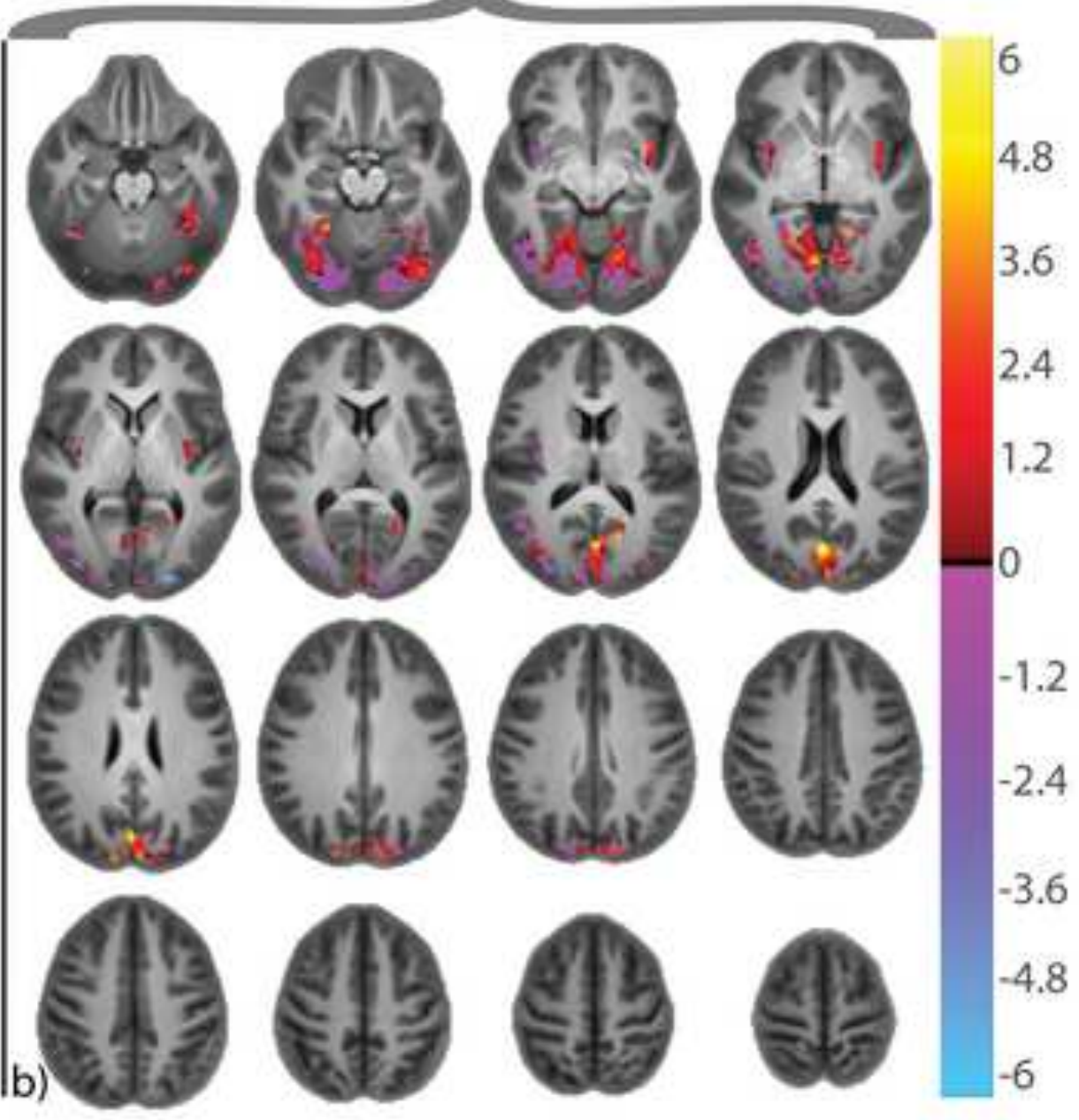




\section{Figure 4

Click here to download high resolution image

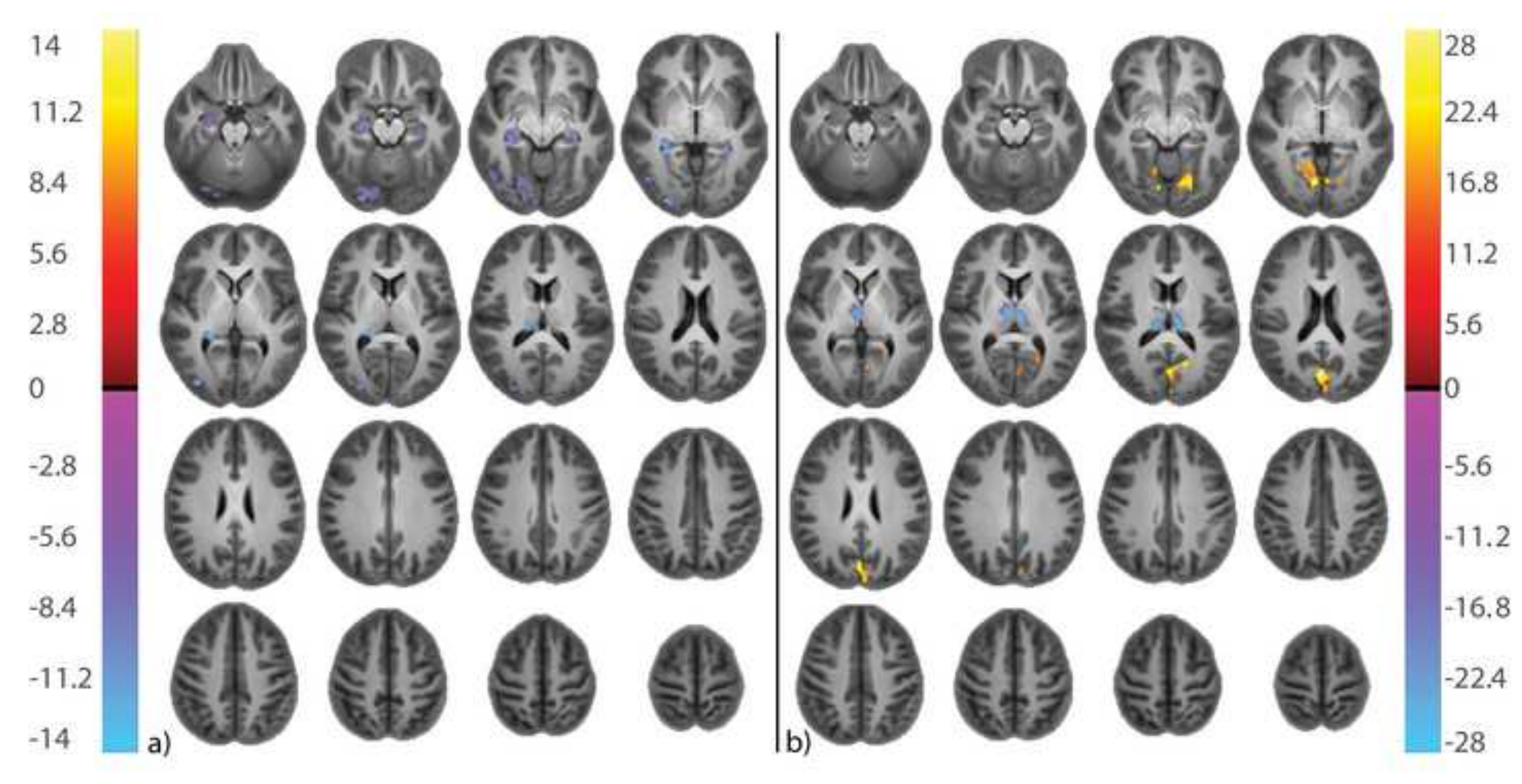

Click here to download high resolution image

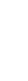


9. Figure 5

Click here to download high resolution image

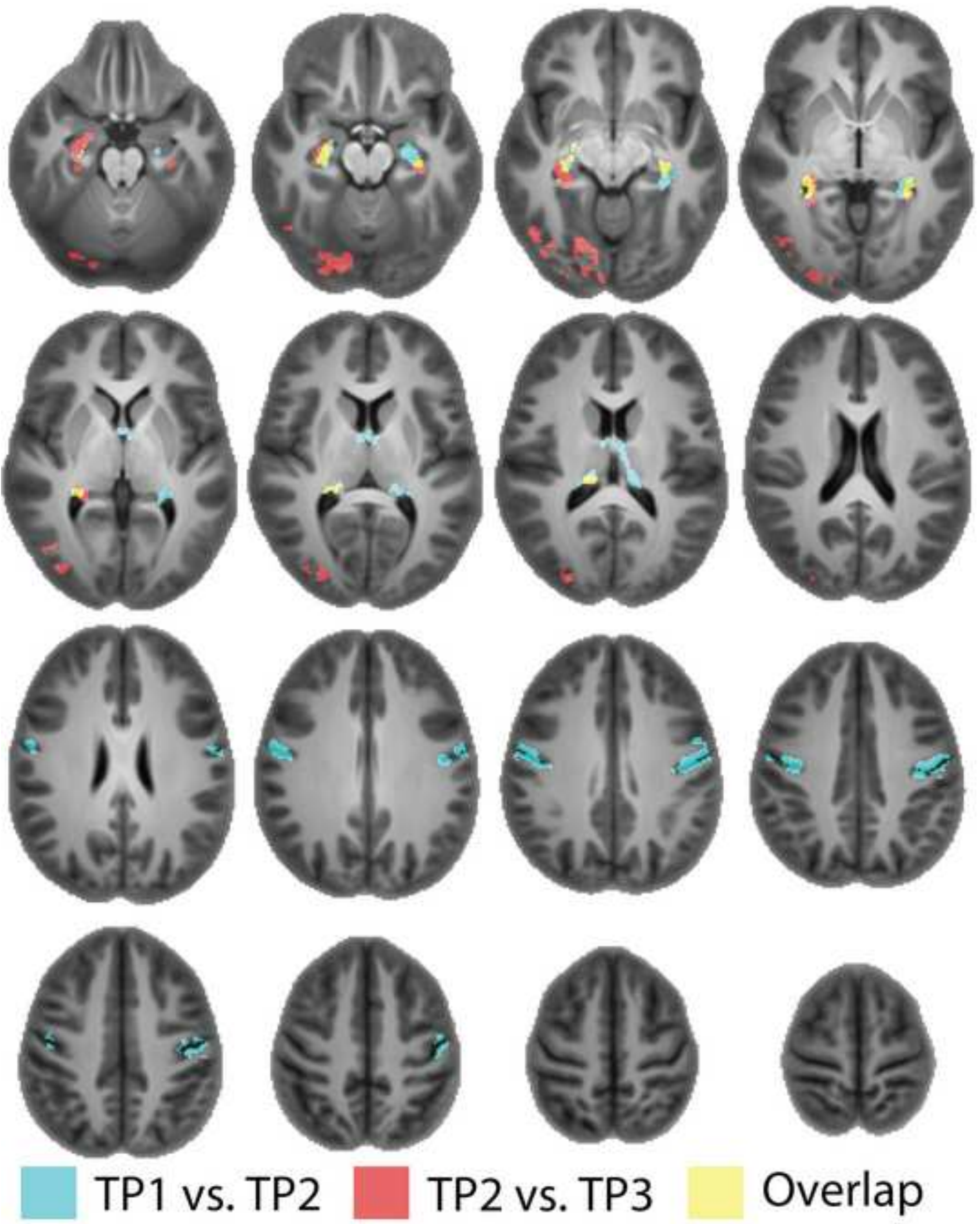




\section{. Figure 6

Click here to download high resolution image

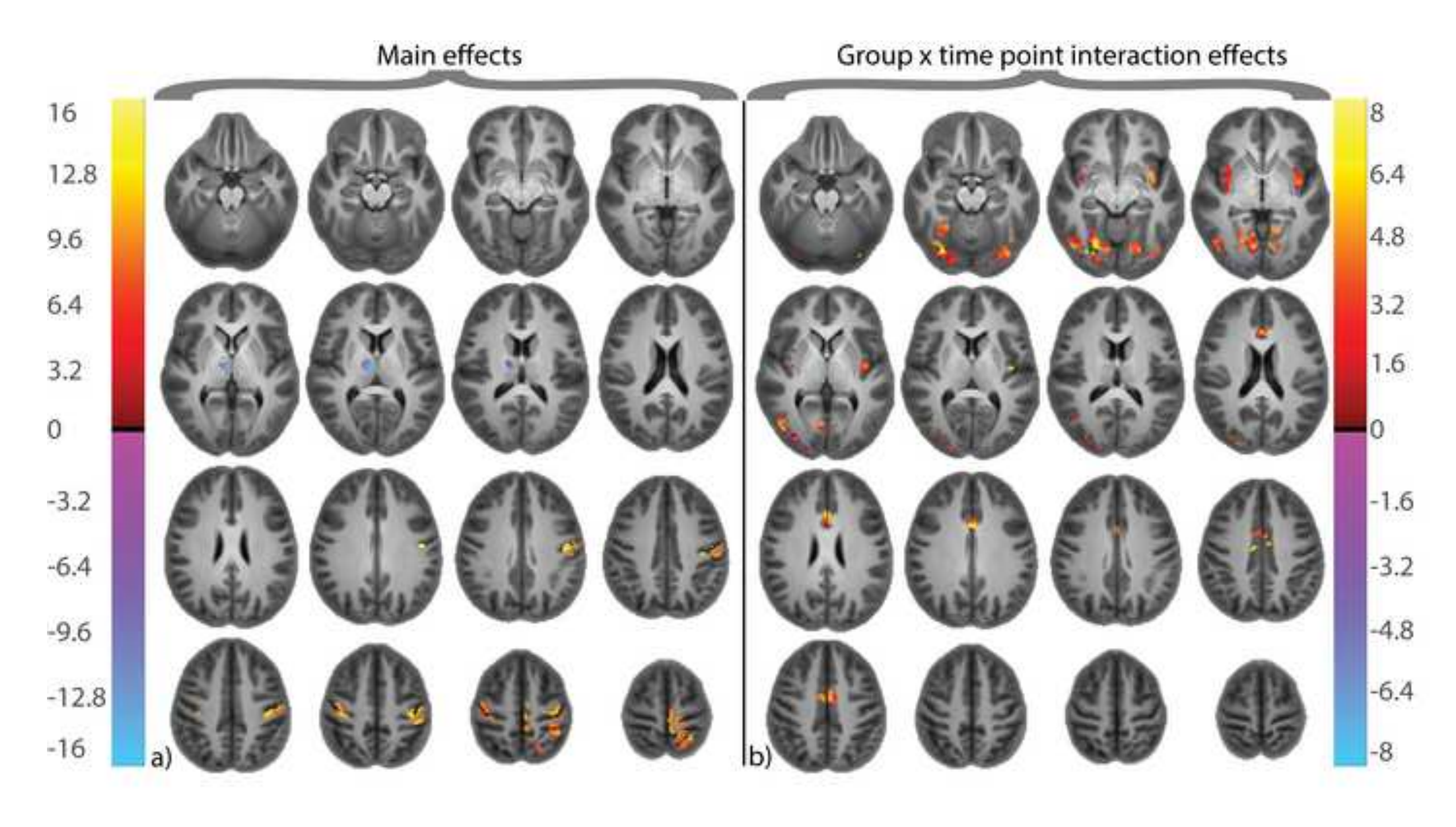

Click here to download high resolution imagr

Main effects




Click here to download high resolution image

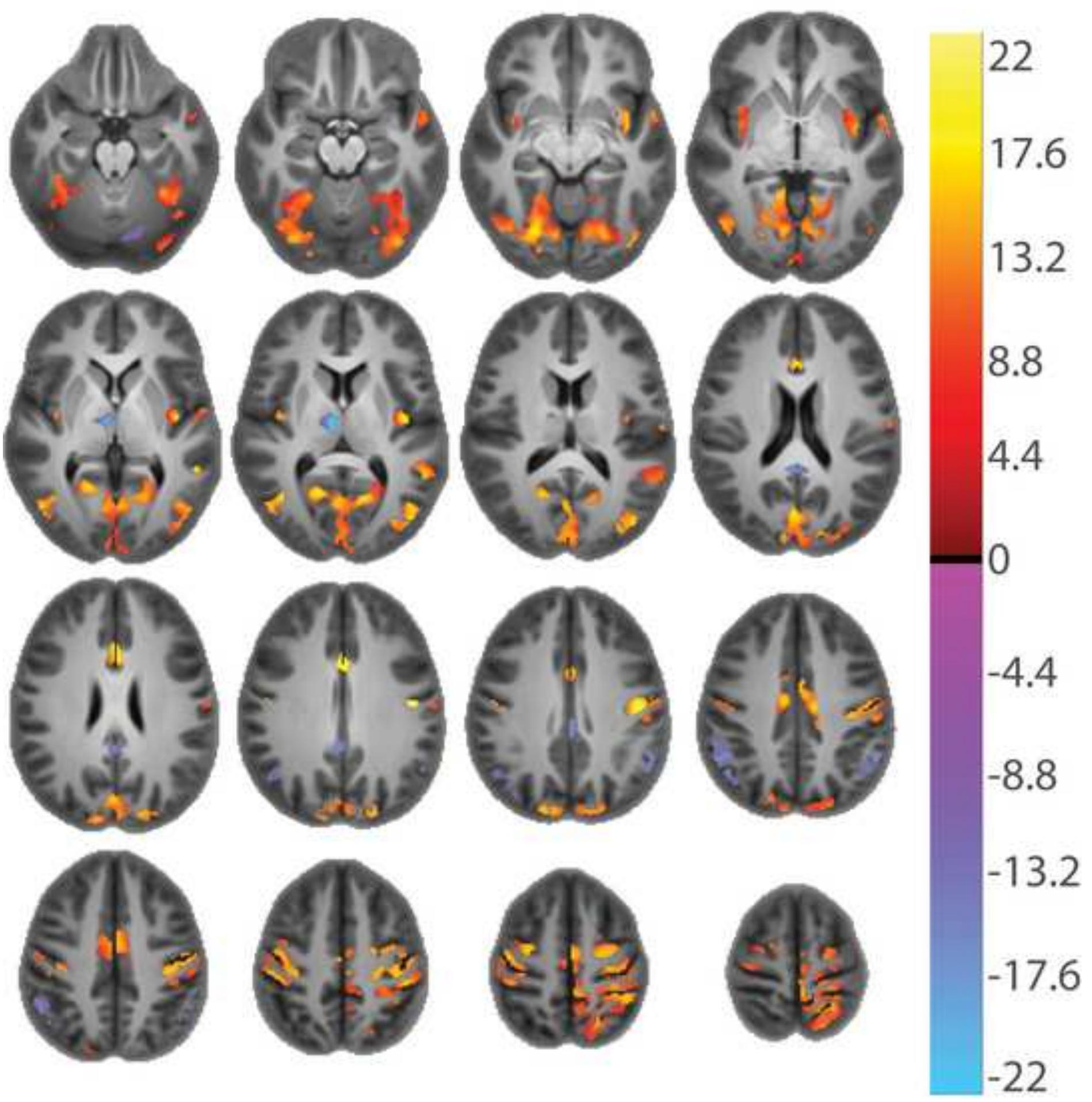


10. Supplementary Material
Click here to download 10. Supplementary Material: Supplement.docx

Click here to download 10. Supplementary Material: Supplement.docx

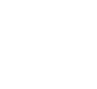

$\sqrt{3}$

(1)
$\sqrt{2}$ (1) (1) (1) (1) . .

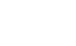

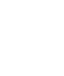

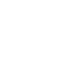

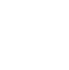

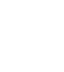

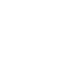

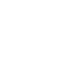

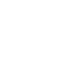

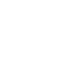

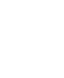

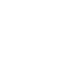

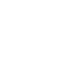

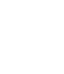

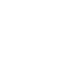

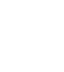

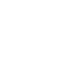

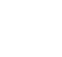
要 (1) 